\title{
Monotonic and cyclic testing of clay brick and lime mortar masonry in compression
}

Jorge Segura $^{\mathrm{a}, *}$, Luca Pelà ${ }^{\mathrm{a}}$, Pere Roca ${ }^{\mathrm{a}}$

${ }^{a}$ Department of Civil and Environmental Engineering, Universitat Politècnica de Catalunya (UPCBarcelonaTech), 08034 Barcelona, Spain

* Corresponding author. Department of Civil and Environmental Engineering, Technical University of Catalonia (UPC-BarcelonaTech), Jordi Girona 1-3, C1, 08034 Barcelona, Spain. E-mail address: jorge.segura@upc.edu

Abstract: This research presents an experimental programme on the mechanical characterization of masonry under monotonic and cyclic uniaxial compression. Two different types of standard specimens, running bond walls and stack bond prisms, were built using handmade clay bricks and hydraulic lime mortar. The experimental results are compared and discussed in terms of strength, stiffness and deformability. It was observed that the two specimen types provided very similar results on both strength and stiffness. Cyclic loading tests carried out on a set of samples provided new experimental evidence on the stiffness degradation, loss of load carrying capacity for increasing irreversible compressive strains and energy dissipation. The paper presents eventually a thorough discussion about the comparison between the obtained experimental results with available predictive models for strength, stiffness and fracture energy of masonry under monotonic and cyclic compression loading.

Keywords: Masonry, clay brick, lime mortar, size effect, compression test, compressive strength, elastic modulus, monotonic loading, cyclic loading, compressive fracture energy.

Highlights:

Compression tests on two different standard masonry specimens yielded similar results 
Tests provided new data on clay brick and lime mortar masonry under cyclic loading

Cyclic tests allowed characterizing the stiffness degradation for increasing strains

Available analytical and empirical models fit the experimental results satisfactorily

\section{Introduction}

Brick masonry has been largely used for structural purposes up to mid-20 ${ }^{\text {th }} \mathrm{c}$ when, due to the increasing labour costs, it became less attractive than other more modern materials such as concrete and steel $[1,2]$. Due to its long historical prevalence, masonry consisting of clay bricks and lime mortar is abundant all over the world. Still today, a significant part of the building stock includes structural masonry members such as load-bearing walls [2-8]. Due to changes in regulations and uses, masonry buildings are often in need of structural re-evaluation and, eventually, of possible retrofitting interventions. Within this context, the response of masonry in compression has a critical role in the evaluation of the strength capacity of masonry buildings against both vertical actions and the vertical load effects caused by horizontal actions. Characterizing the response of masonry in compression involves the determination of parameters such as the compressive strength of the composite material, its modulus of elasticity and the overall stress-strain curves in compression under both static and cyclic loading.

Traditionally, the characterization of the mechanical behaviour of masonry in compression has been carried out by means of tests performed on two different types of composite specimens, namely stack bond prisms and small walls. Three recent references [9-11], including inventories of past researches on clay brick masonry, refer examples of tests done on either specimen type, although with preference for prims. The predilection to carry tests on prisms can be explained because they are easier and cheaper to build and the experimental setup needed in the laboratory is simpler.

The possibility of testing two different types of specimen is also reflected in the standards that regulate the experimental determination of the compressive strength of masonry $\left(f_{c}\right)$. The European 
standard EN 1052-1 [12] prescribes the use of small running bond walls with certain geometric constraints (Fig. 1a). These samples are supposed to provide a fair estimation of the strength taking into account the possible detrimental influence of head mortar joints. In addition, they are sufficiently slender as to keep the centre of the specimen free from the influence of possible 3D confinement effects caused by the contact between the specimen and the press platens. Conversely, the American ASTM C1314 [13] proposes the possibility of testing simpler stack bond prisms consisting of a sufficient number of stacked units. The standard specifies the recommended height to thickness ratios of the prisms (Fig. 1b). In turn, both types of specimens are considered in the RILEM [14] recommendations.
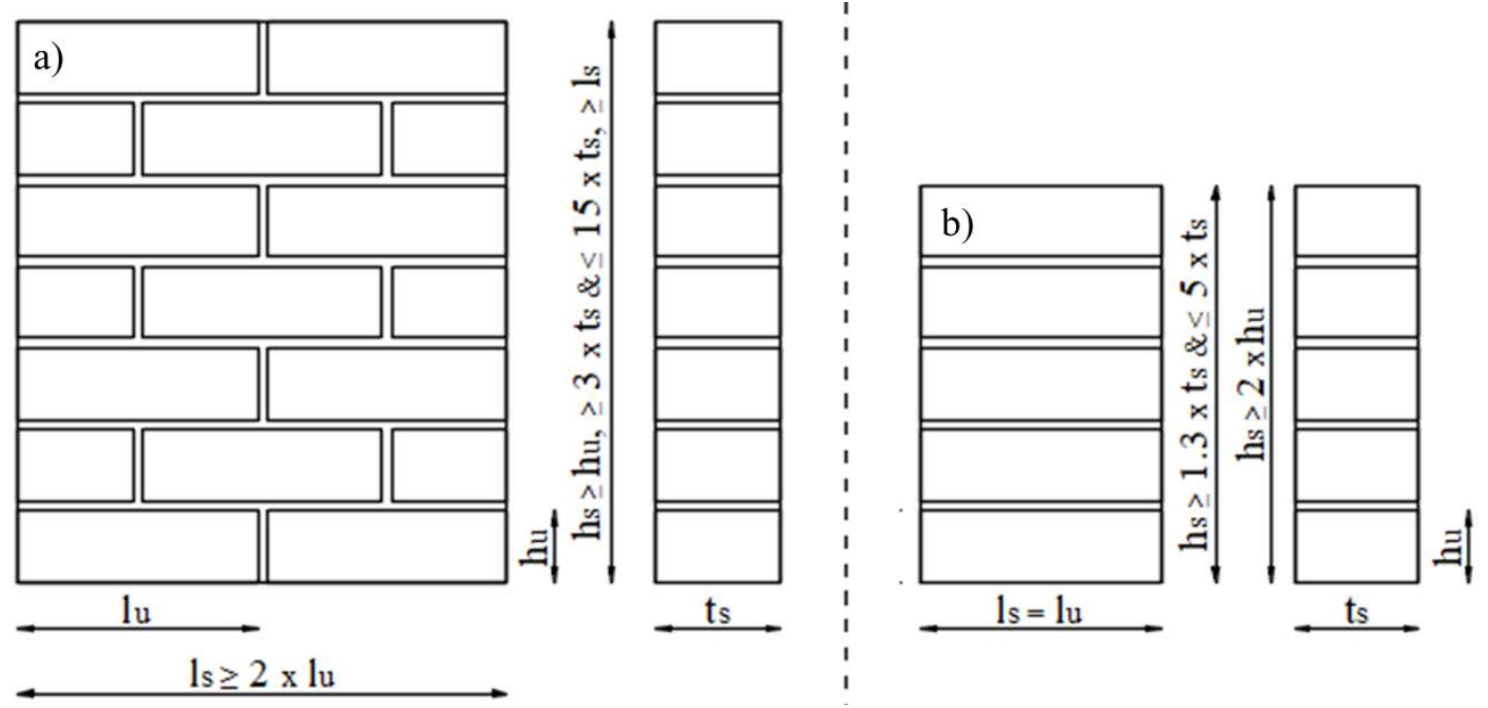

Fig. 1. Masonry specimens for compression strength tests according to a) EN 1052-1 [12], b) ASTM C1314 [13].

So far, no empirical criterion has been proposed to correlate the experimental results obtained with both specimen types. However, this issue has motivated some research in the past. Several authors [15-17] have compared the results on prisms with those obtained for wall-like samples. Mann \& Betzler [18] and Gumaste et al. [19] investigated the effect of the sample shape on the compressive strength. Among other specimen types, they analysed the case of non-standardized both stack bond prisms and running bond walls. They showed that the comparison between the specimens' results is influenced by the mechanical properties of the constituents, as well as by the specimens' relative slenderness. 
Many real structures are subjected to cyclic loading caused by variable loads such as thermal effects, the passing of trains on railway bridges, or seismic actions. However, most of the research effort on the compressive behaviour of masonry has only focused on monotonic loading [20]. A few works can be found on cyclically loaded stone [21-23] and concrete block masonry [24]. With regard to brick masonry, $[25,26]$ carried out pioneering researches on frogged clay and sand-plast brick masonry specimens. These authors developed the concepts of common and stability points to characterize the intersections among unloading-reloading branches in masonry. More recently, [27,28] contributed with more laboratory results, and [23] explored the possibility of performing and registering cycles in the softening range. Two more researches $[7,29]$ dealt with samples obtained from historical buildings, while [30] is the only study including masonry built in the laboratory with solid clay bricks and hydraulic lime based mortar without cement.

This paper aims to provide new experimental data on the static and cyclic response of brick masonry in compression. The paper focuses on the case of masonry built with solid clay bricks and hydraulic lime based mortar, on which there is still limited experimental evidence although being the traditional typology in historical masonry in many countries [29,31,32]. The research on the static response includes a comparison of results on the masonry compressive strength and elastic modulus for two different types of standardized specimens, corresponding to stack bond prisms and running bond walls. In turn, the research on the cyclic response includes cyclic tests up to and beyond the peak load on stack bond prisms. The performance of different criteria and models for the estimation of the masonry compressive properties and the simulation of its cyclic response has been evaluated by comparison with the experimental results.

\section{Experimental programme}

The experiments were carried out at the Laboratory of Technology of Structures and Materials of the Technical University of Catalonia (UPC - BarcelonaTech). As mentioned, the experimental 
programme included compression tests on two different types of specimens (running bond walls and stack bond prisms), under monotonic and cyclic loading.

\subsection{Materials}

The masonry specimens were built with materials similar to those existing in historical masonry walls, including handmade solid clay bricks and a low mechanical performance lime mortar.

Handmade fired solid clay bricks were chosen, with average dimensions of 311 (length) x 149 (width) x 45 (height) $\mathrm{mm}^{3}$ and density of $1700 \mathrm{~kg} / \mathrm{m}^{3}$. Given their manual way of manufacturing, these bricks presented a moderate compressive strength, rough surfaces and slightly variable dimensions. A commercial premixed lime mortar based on NHL 3.5 natural hydraulic lime was selected. Its strength category was M5, which was considered to be too high to reproduce the expected compressive strength of lime mortar in historical masonry. Hence, a new mix was studied and prepared in laboratory by adding an amount of non-reactive material (in this case, limestone filler) to reduce the strength of the mortar. The volume ratio of premixed mortar to filler to water was $1: 1: 0.65$.

The standard EN 772-1 [33] was considered as reference to obtain the normalized compressive strength of the bricks $\left(f_{b}\right)$. Their faces were polished until getting a constant height of $40 \mathrm{~mm}$ to obtain flat surfaces. Pieces of $100 \times 100 \mathrm{~mm}^{2}$ were cut to fulfil the minimum height to width ratio of 0.4 required by the standard and then tested. The measured strength values were corrected by applying a shape factor of 0.7 in compliance with the standard. The bending tensile strength of the units $\left(f_{b, f l}\right)$ was determined by three-point-bending tests on full bricks. In the lack of a specific standard for the determination of the bending tensile strength of clay units, the tests were carried out according to EN 772-6 [34] for aggregate concrete masonry units. Similarly, and since there are no available standards on the determination of the elastic modulus of bricks, EN 12390-13 [35] on the determination of the modulus of elasticity for hardened concrete was used as a reference. Brick prisms measuring 40 x 40 x $80 \mathrm{~mm}^{3}$ were cut both in longitudinal and transverse directions of the unit. It should be noted that 
measuring the modulus of the bricks in the direction parallel to the load is hardly feasible due to their very small height. Three loading-unloading compressive cycles, with minimum and maximum loads equal to $10 \%$ and $30 \%$ of the estimated peak load, were applied to the specimens. The moduli of elasticity in the two directions ( $E_{b \text {,long }}$ and $\left.E_{b, \text { trans }}\right)$ were evaluated as the slope of the last reloading branches as suggested in the standard [35]. The results of this characterization are presented in Table 1. The considerably high coefficients of variation found in the determination of the elastic modulus may be explained by the heterogeneity of the handmade bricks. In addition to the scattering related to the raw materials, the manual process adds variability during the casting of the bricks and the curing inside the traditional furnace.

Table 1. Mechanical parameters of bricks

\begin{tabular}{ccccc}
\hline & $f_{b}[\mathrm{MPa}]$ & $f_{b, f l}[\mathrm{MPa}]$ & $E_{b, \text { long }}[\mathrm{MPa}]$ & $E_{b, \text { trans }}[\mathrm{MPa}]$ \\
\hline Average & 17.99 & 2.44 & 3718 & 3331 \\
Number of samples & 20 & 10 & 12 & 17 \\
$\mathrm{CV}$ & $8.3 \%$ & $20.0 \%$ & $28.0 \%$ & $51.4 \%$ \\
\hline
\end{tabular}

The compressive strength $\left(f_{m}\right)$ and the bending tensile strength $\left(f_{m, f l}\right)$ of the mortar were evaluated according to EN 1015-11 [36], by using prisms with dimensions of 160 x 40 x $40 \mathrm{~mm}^{3}$ that were casted with mortar obtained from the mason's batch during the construction of the masonry specimens. As for the evaluation of bricks elastic modulus, EN 12390-13 [35] was adopted as reference. The estimation of the mortar elastic modulus $\left(E_{m}\right)$ was carried out on mortar cylinders $200 \mathrm{~mm}$ high with a diameter of $100 \mathrm{~mm}$. These cylinders were tested under cyclic loading similarly to the brick prisms. A summary of the results is presented in Table 2.

Table 2. Mechanical parameters of mortar

\begin{tabular}{cccc}
\hline & $f_{m}[\mathrm{MPa}]$ & $f_{m, f l}[\mathrm{MPa}]$ & $E_{m}[\mathrm{MPa}]$ \\
\hline Average & 1.91 & 0.72 & 948 \\
Number of samples & 36 & 18 & 6 \\
$\mathrm{CV}$ & $10.1 \%$ & $10.9 \%$ & $18.4 \%$ \\
\hline
\end{tabular}

\subsection{Masonry specimens}


Two different sets of masonry specimens were built and tested. The first set consisted of 4 standard running bond walls (RBW) fulfilling the requirements of EN 1052-1 [12]. The second set consisted of 7 stack bond prisms (SBP) built according to the geometric prescriptions of ASTM C 1314 [13]. As previously indicated, one of the aims of the present research lays in the comparison of the strength and elasticity parameters measured by means of these two types of standardized specimens. The average dimensions of both types of samples are 639 (length, $l_{s}$ ) x 148 (thickness, $t_{s}$ ) x 658 (height, $h_{s}$ ) mm ${ }^{3}$ for walls, with aspect ratio $\left(h_{s} / t_{s}\right)$ of 4.45 , and $312 \times 148 \times 288 \mathrm{~mm}^{3}$ for prisms, with aspect ratio $\left(h_{s} / t_{s}\right)$ of 1.95 (Fig. 2). The samples were built with $15 \mathrm{~mm}$ thick mortar joints. This thickness, which is often observed in historical clay brick masonry, allowed a sufficiently regular laying of bricks despite of the geometrical irregularities of their faces.
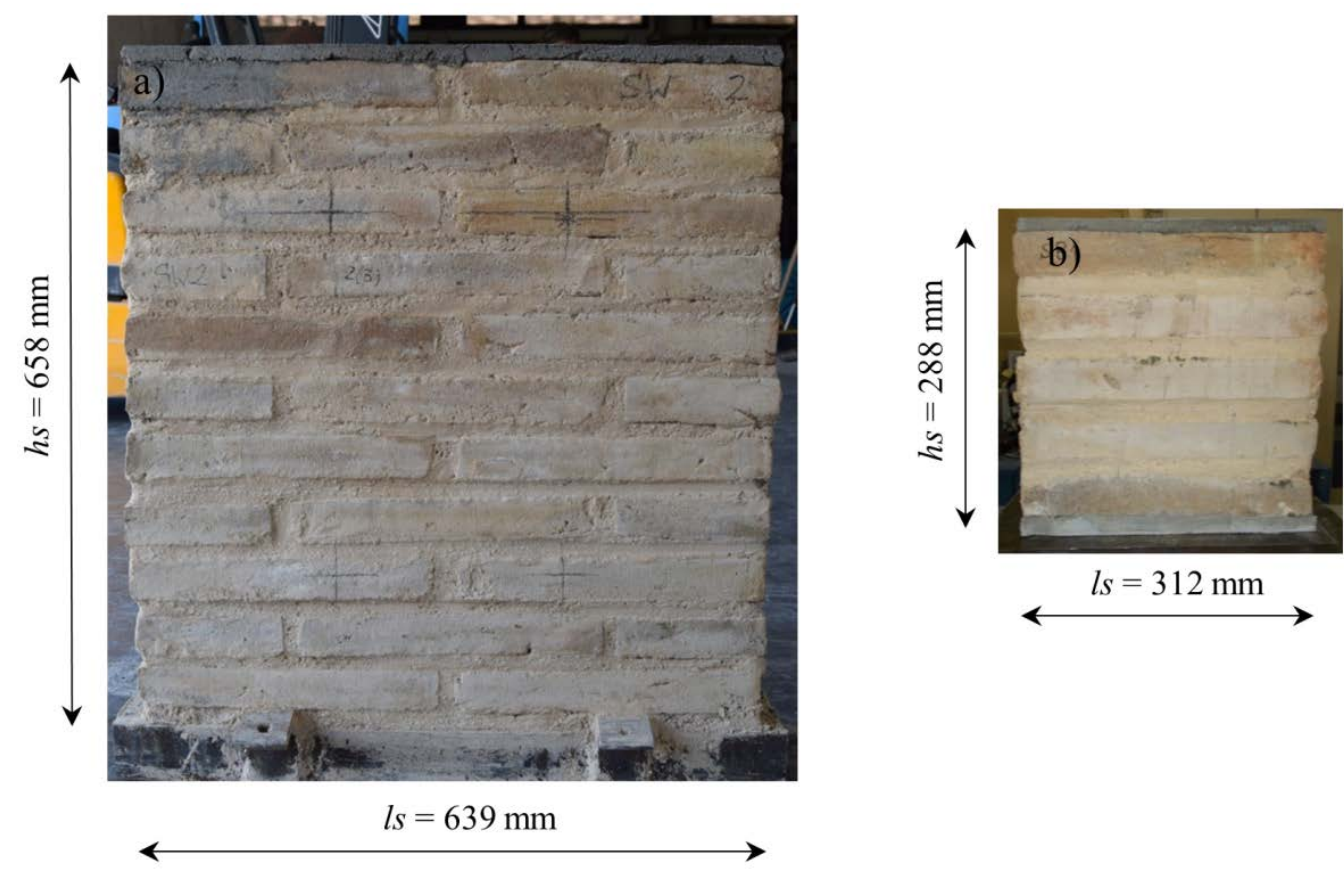

Fig. 2. Masonry samples, average dimensions. a) Running bond walls, b) Stack bond prisms. Common average thickness

$$
t_{\mathrm{s}}=148 \mathrm{~mm}
$$

The building and storing of the specimens were carried out according to EN 1052-1 [12]. The bricks were wetted for one minute before being laid. The samples were all built during the same day, by the same highly qualified mason, and stored under the same environmental conditions until the 
performance of the tests. After construction, they were covered with polyethylene sheets in order to prevent the dry-out of the mortar. After 3 days, they were uncovered and stored in the laboratory at 15 ${ }^{\circ} \mathrm{C}$ and $65 \%$ of relative humidity.

With the aim of facilitating the handling of the RBW wall specimens, they were built and tested on top of metallic beams filled with concrete. Some days before testing, the top face of the RBWs, as well as the bottom and top faces of the SBPs, were capped with a layer of high strength cement mortar in order to ascertain a smooth contact between the samples and the loading machine plates.

\subsection{Test procedures}

The wall and prism masonry samples were tested in compression after 28 days from their construction, following EN 1052-1 [12] recommendations. The prisms SBP were tested in a generalpurpose loading machine with a capacity of $3000 \mathrm{kN}$ (Fig. 3a). The walls RBW had to be tested inside a steel reaction frame due to their larger dimensions. In the reaction frame, the load was applied by means of a double effect hydraulic jack with capacity of $1000 \mathrm{kN}$ (Fig. 3b). A combination of instruments was placed on the specimens' faces in order to capture vertical displacements. Four LVDTs (with a displacement range of $+/-5 \mathrm{~mm}$ and a precision of $5 \mu \mathrm{m}$ ) were glued between the second and fourth bricks of the SBPs. They allowed having a reference length longer than one third of the sample height while avoiding possible boundary effects. The same distance was also monitored in the case of RBWs with a vertical LVDT placed on each face. This allowed obtaining comparable measurements in the two specimen types, with the difference that a head mortar joint was included in the walls. 

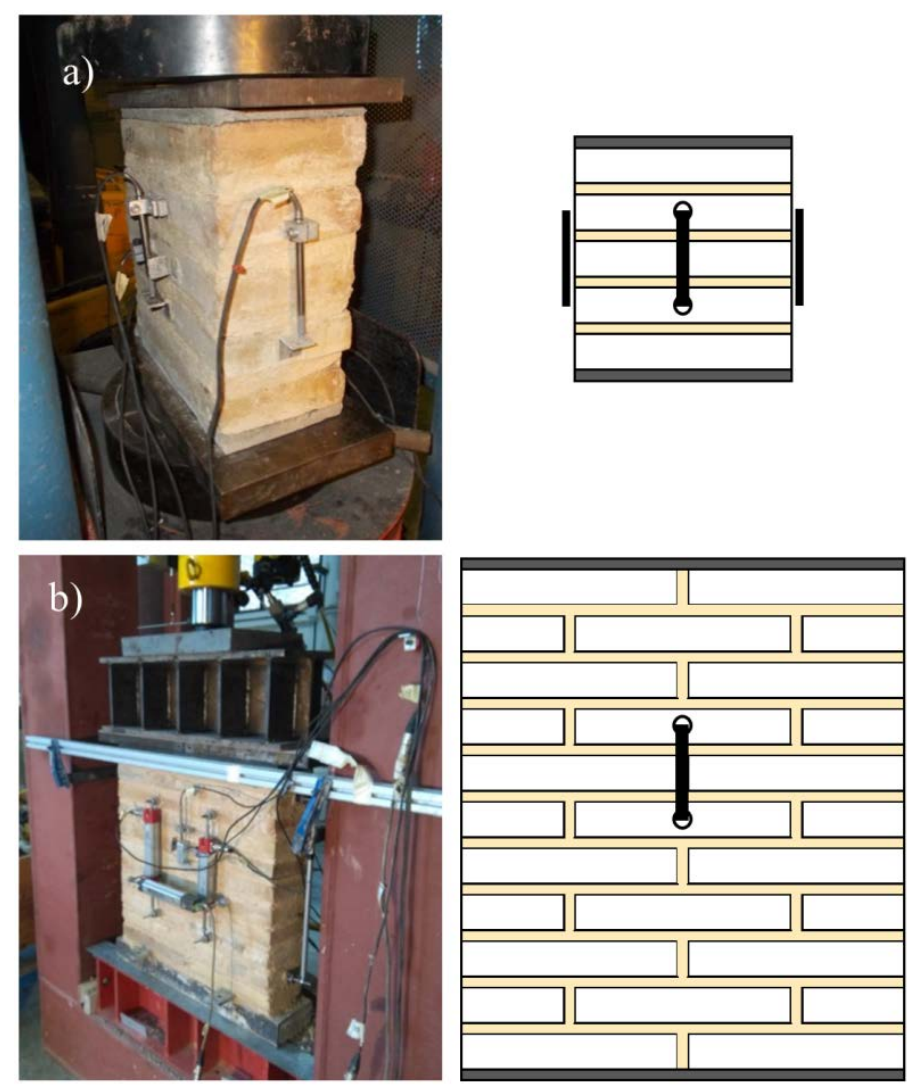

Fig. 3. Experimental setups: a) Stack bond prisms, b) Running bond walls.

The tests were carried out in two stages (Fig. 4), the first one was aimed to facilitate the measurement of the elastic modulus of masonry and the second one investigated its ultimate capacity. In the lack of a specific standard on the measurement of the elastic modulus of masonry, the procedure adopted during the first stage was based on standards for the determination of the elastic modulus in other materials such as concrete (EN 12390-13 [35], ASTM C 469-02 [37]) and stone (EN 14580 [38]), and also on methods applied in former researches [17,20,39].

The first stage was common to all the specimens and included three loading-unloading cycles performed under load control. The lower and higher load levels applied during the cycles were set to $5 \%$ and $30 \%$ of a supposed maximum load $\left(P_{o}\right)$ that had been estimated before the tests. In the case of the walls, these limits were taken as 26 and $150 \mathrm{kN}$, while for the prisms the limits were 14 and $83 \mathrm{kN}$. Rates of loading of $2 \mathrm{kN} / \mathrm{s}$ and $1 \mathrm{kN} / \mathrm{s}$ were selected for walls and prisms respectively to keep the duration of the loading/unloading branches around 1 minute. After each loading/unloading branch, the 
load level was maintained also for 1 minute. As stated by the general standard ASTM E111 [40], the lower load was used to minimize the errors due to initial effects of backlash and specimen irregularities while the upper load was selected so as to keep the specimen within the elastic range of the material.

The second stage of the tests explored the strength and non-linear behaviour of the specimens under either monotonic or cyclic loading. A displacement controlled loading procedure (at a rate of $0.6 \mathrm{~mm} / \mathrm{s}$ ) was used during this stage with the intention of capturing the post-peak response. This phase was undertaken under monotonically increasing displacement for the 4 running bond walls (identified as RBW1, RBW2, RBW3, RBW4) and for 4 stack bond prisms (SBP1, SBP2, SBP3, SBP4).

In the remaining three stack bond prisms (SBP5, SBP6, SBP7), the displacement was imposed cyclically. The aim of these tests was not to represent any example of real structures, which may be subjected to cyclic loads characterized by very different frequencies and amplitudes, but to study a generic case. The type and number of cycles was decided as to have comparable results with former researches [23]. The system was programmed to apply increasing load up to vertical displacement values of 2.5, 4, 5.5, 7, and $8.5 \mathrm{~mm}$. These values were defined based on the results of the previous monotonic tests. Once those displacements were reached, the specimens were unloaded under force control until the previously set level of $5 \%$ of the estimated maximum load. The vertical displacement was controlled by the loading machine’s internal transducer.

With regard to the elastic moduli, they were evaluated for all the specimens as the chord modulus between the $5 \%$ and $30 \%$ of the actual maximum load $\left(P_{\max }\right)$ (Fig. 4), of the stress-strain curves obtained during the second testing stage. 


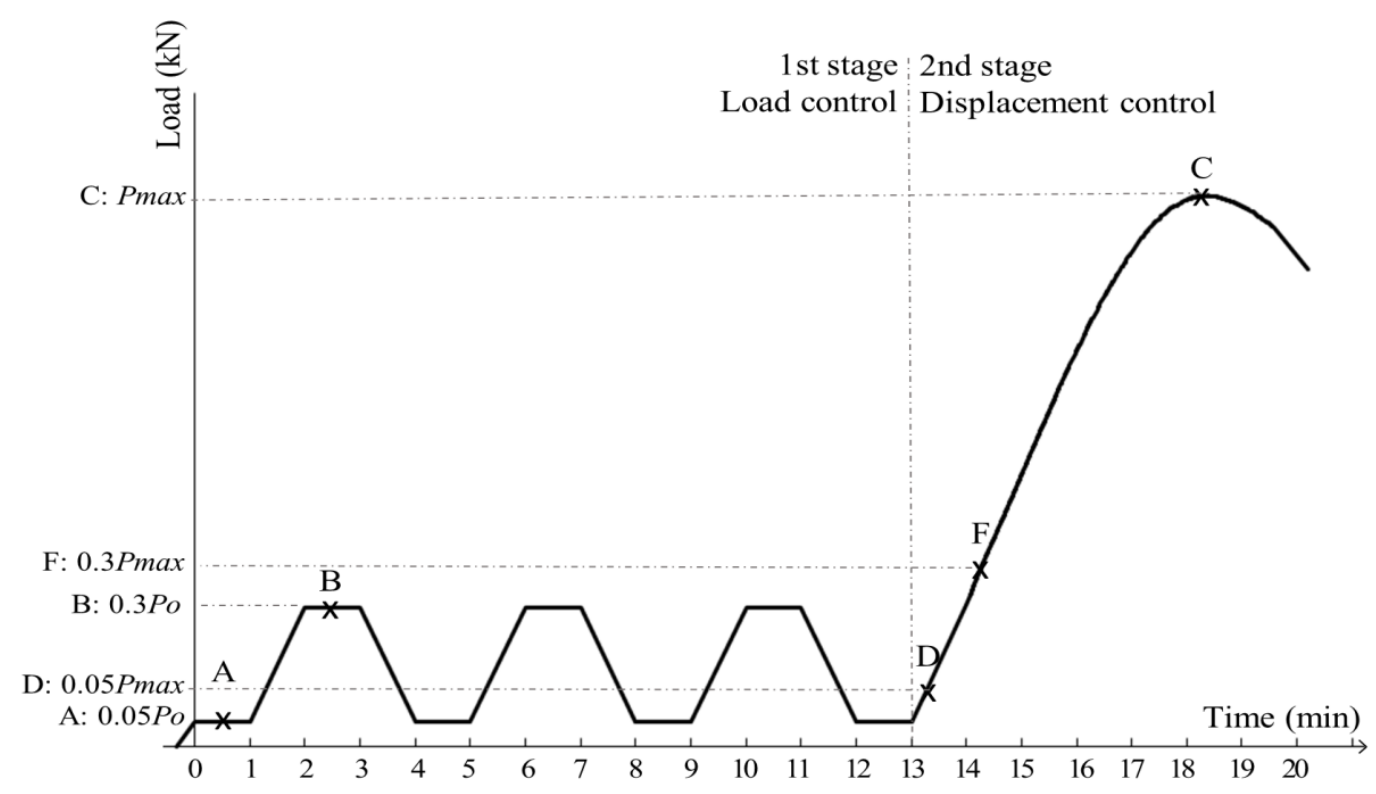

Fig. 4. Generic load (kN) vs. time (min) curve describing the adopted loading history. Load levels: A - 5\% of an estimated maximum load $\left(P_{o}\right)$. B - 30\% of an estimated maximum load $\left(P_{o}\right)$. C - Actual maximum load registered during the test $\left(P_{\max }\right)$. D and F - Loads corresponding to $5 \%$ and $30 \%$ of the actual maximum load $\left(P_{\max }\right)$, used as limits to compute the elastic modulus on the stress-strain curves.

\section{Experimental results}

This section presents the results of the experimental campaign for each type of specimen and loading protocol. Compressive stresses acting on the samples were computed as the ratio between the applied load and the area of the cross section. LVDT readings were divided by their reference lengths and averaged to obtain axial strains. In some cases, anomalous individual deviations of one LVDT were omitted. Full stress-strain curves, considering both stages of testing, are plotted for all the tests. As for the post-peak branches, they are only shown for the cases in which it was possible to obtain meaningful results.

\subsection{Running bond walls}

The stress-strain curves resulting for both stages are shown in Fig. 5, for the RBW specimens. The effect of the application of the three cycles is illustrated in Fig. 5a. The unloading-reloading branches have higher stiffness than the original monotonic loading one. The elastic moduli $\left(E_{c}\right)$ reported in 
Table 3 were evaluated according to the procedure indicated in section 2.3. The average value is 2744 MPa. However, the result associated to sample RBW3 is anomalously high compared to the other specimens. This high value may be explained by a possible better manufacture or by an unexpected localization of better quality materials within the length captured by the measuring instruments. Due to the significant deviation of this value with respect to the remaining set of values, it has been deemed preferable to also calculate the average value of the elastic modulus without taking it into account. The value of this second calculated average is $2318 \mathrm{MPa}$. This has been the value considered in the discussions presented in sections $\mathbf{4}$ and 5. Other RBW3 results, such as the compressive strength and the strain at peak stress, are considered sufficiently representative and have not been disregarded in the calculation of the corresponding averages. Globally, the curves depicted in Fig. $5 \mathbf{b}$ continue to be linear up to around $2 \mathrm{MPa}$ and then experience a progressive reduction of the stiffness until the peak stress. Table 3 presents the values of the compressive strengths $\left(f_{c}\right)$ and the strains at the peak stresses $\left(\varepsilon_{p}\right)$. The average strength is $6.51 \mathrm{MPa}$ and the average strain at peak stress is $0.98 \%$.
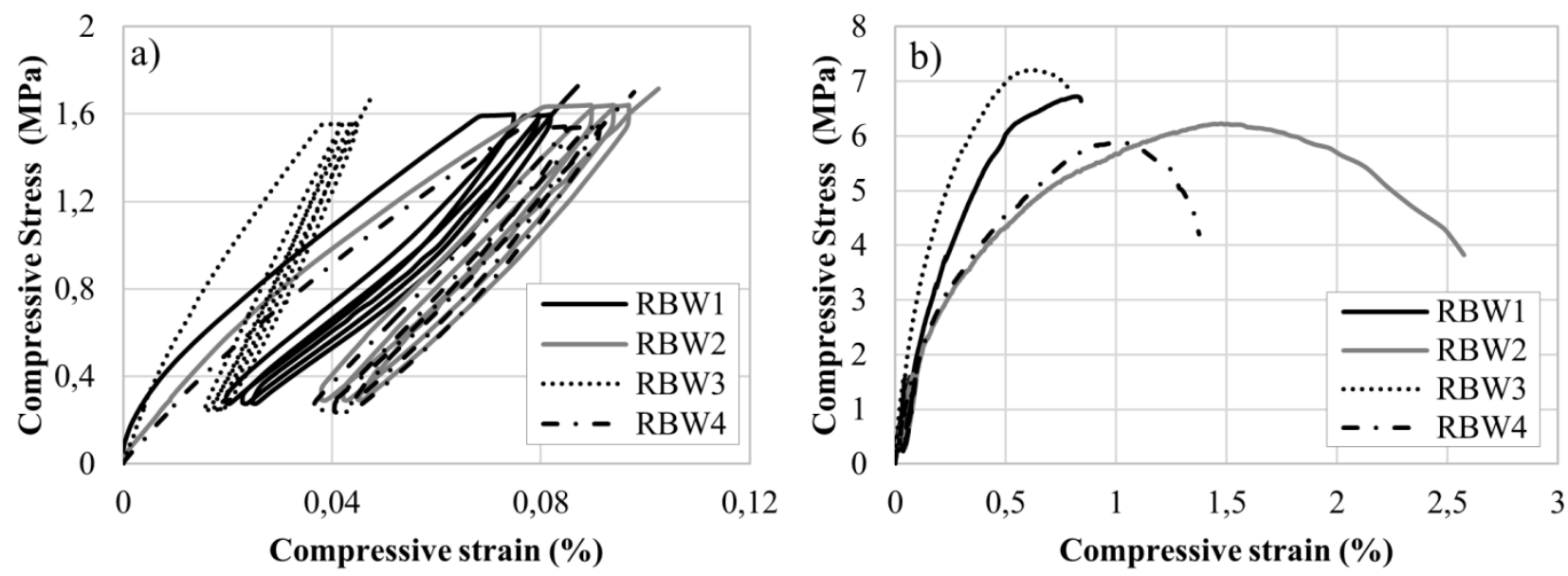

Fig. 5. Stress vs. strain experimental curves for running bond walls. a) Detail of the three loading/unloading cycles, b) Full curves until failure.

Table 3. Compressive strength, stiffness and strain at peak stress of running bond walls.

\begin{tabular}{cccc}
\hline$R B W$ & $f_{c}(\mathrm{MPa})$ & $E_{c}(\mathrm{MPa})$ & $\varepsilon_{p}(\%)$ \\
\hline$R B W 1$ & 6.72 & 2205 & 0.82 \\
$R B W 2$ & 6.22 & 2227 & 1.48 \\
$R B W 3$ & 7.20 & 4023 & 0.62
\end{tabular}




\begin{tabular}{cccc} 
RBW 4 & 5.88 & 2521 & 1.00 \\
Average & 6.51 & 2744 & 0.98 \\
$C V$ & $8.9 \%$ & $31.5 \%$ & $37.6 \%$ \\
\hline Average & $2318^{*}$ \\
$C V$ & $7.6 \%{ }^{*}$ \\
\hline${ }^{*}$ The value of $E_{c}$ for RBW3 is not considered in the average.
\end{tabular}

The failure mode of the RBWs was qualitatively similar for the 4 samples. The first visible cracks appeared at about $75 \%$ of the maximum load. These cracks were thin and vertical, initially only visible in the bricks and mostly located in the external thirds of the front faces of the specimens. At the peak load, the cracks were wider and visibly affected both bricks and mortar (Fig. 6a). After the peak, degradation continued, with further opening of the cracks and sudden spalling of mortar and brick portions. In two samples, sudden transverse splitting, visible from the lateral faces, was produced (Fig. 6b). Once dismantled (Fig. 6c), the specimens exhibited a typical sandglass failure, characterized by the presence of a remaining core.
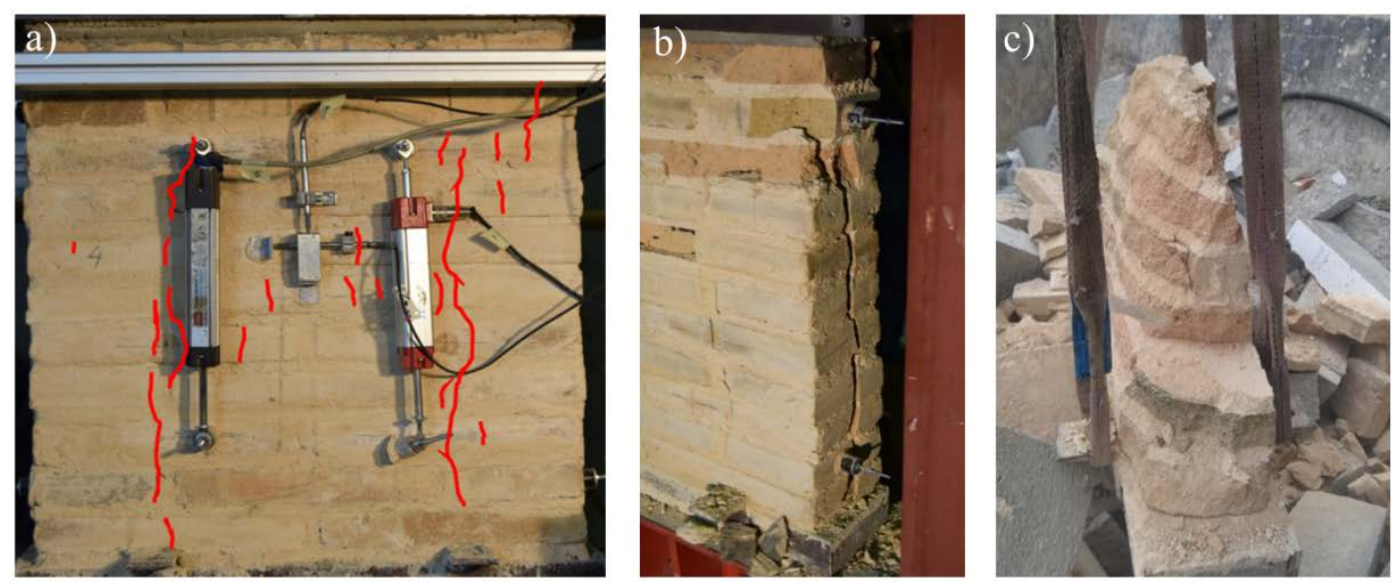

Fig. 6. Failure of running bond walls. a) Crack pattern at peak load, b) State at the end of the test, c) Dismantled specimen.

\subsection{Stack bond prisms - Monotonic loading}

Among the 7 stack bond prisms prepared, 4 were tested following the same procedure applied to the running bond walls. After the first stage, involving three cycles under load control, they were subjected to a steadily increasing imposed displacement. The experimental stress-strain curves are 
displayed in Fig. 7. Although SBP3 presents a longer linear branch, all 4 specimens have a noticeable non-linear behaviour. Significant deformability is observed after $65 \%$ of the maximum load, particularly for specimens SBP1 and SBP2. Table 4 reports a summary of the experimental results, which yielded an average elastic modulus of $2494 \mathrm{MPa}$, compressive strength of 6.49 MPa, and strain at peak stress of $1.2 \%$.
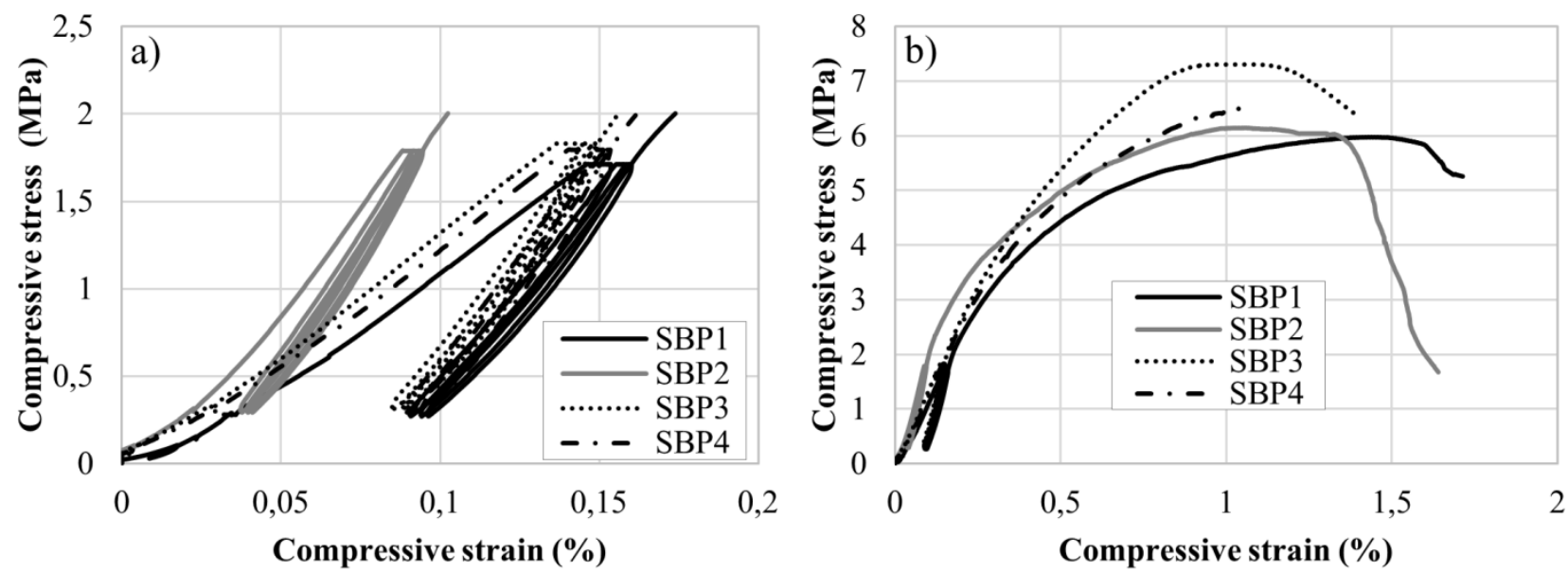

Fig. 7. Stress vs. strain experimental curves of the stack bond prisms with monotonic loading. a) Detail of the three loading/unloading cycles and beginning of the second stage, b) Full curves until failure.

Table 4. Compressive results of stack bond prisms.

\begin{tabular}{cccccccc}
\hline $\begin{array}{c}\text { SBP } \\
\text { mono }\end{array}$ & $f_{c}(\mathrm{MPa})$ & $E_{c}(\mathrm{MPa})$ & $\varepsilon_{p}(\%)$ & $\begin{array}{c}S B P \\
\text { cyclic }\end{array}$ & $f_{c}(\mathrm{MPa})$ & $E_{c}(\mathrm{MPa})$ & $\varepsilon_{p}(\%)$ \\
\hline SBP 1 & 5.98 & 2249 & 1.45 & SBP 5 & 6.91 & 1957 & 0.90 \\
SBP 2 & 6.15 & 2782 & 1.05 & SBP 6 & 7.34 & 2549 & 1.09 \\
SBP 3 & 7.31 & 2443 & 1.10 & SBP 7 & 7.03 & 2634 & 1.00 \\
SBP 4 & 6.52 & 2502 & 1.05 & & & & \\
Average & 6.49 & 2494 & 1.16 & Average & 7.10 & 2380 & 1.00 \\
CV & $9.1 \%$ & $8.8 \%$ & $16.4 \%$ & CV & $3.1 \%$ & $15.5 \%$ & $9.4 \%$ \\
\hline
\end{tabular}

The mechanical behaviour and failure of the stack bond prisms are illustrated in Fig. 8. Before the peak load, vertical cracks developed in the bricks, mainly on the three central ones and near the edges of the faces. After the peak load, these cracks propagated and opened leading to the spalling of some brick and mortar portions. A remaining core forming a sandglass shape could be observed for some of the specimens (Fig. 8c). 

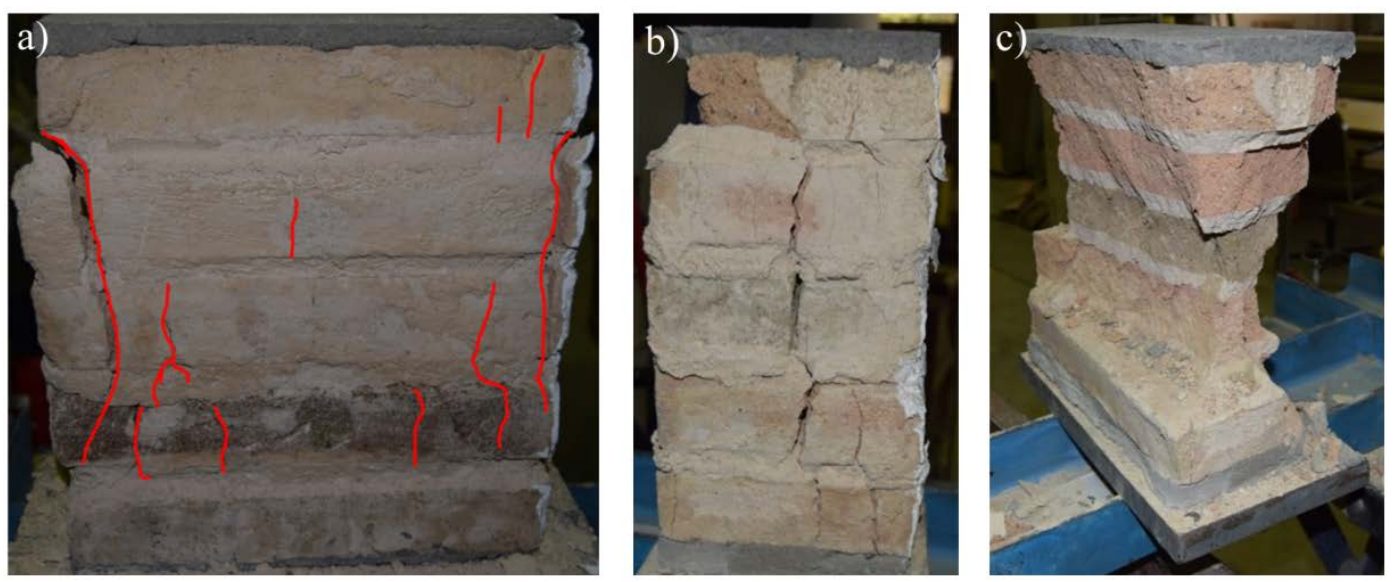

Fig. 8. Stack bond prisms after failure. a) Front view, b) Lateral view, c) Dismantled specimen.

\subsection{Stack bond prisms - Cyclic loading}

As explained in section 2.3, three stack bond prisms were tested cyclically at the second loading stage until displacement controlled failure. As shown in Fig. 9, the stress-strain curves of specimens SBP5 and SBP6 present a complete set of 8 cycles, composed of the three initial ones corresponding to the first stage, two more cycles on the pre-peak range and three additional cycles after the peak load. The post-peak response of specimen SBP7 could not be plotted since it was not properly captured by the LVDTs. 

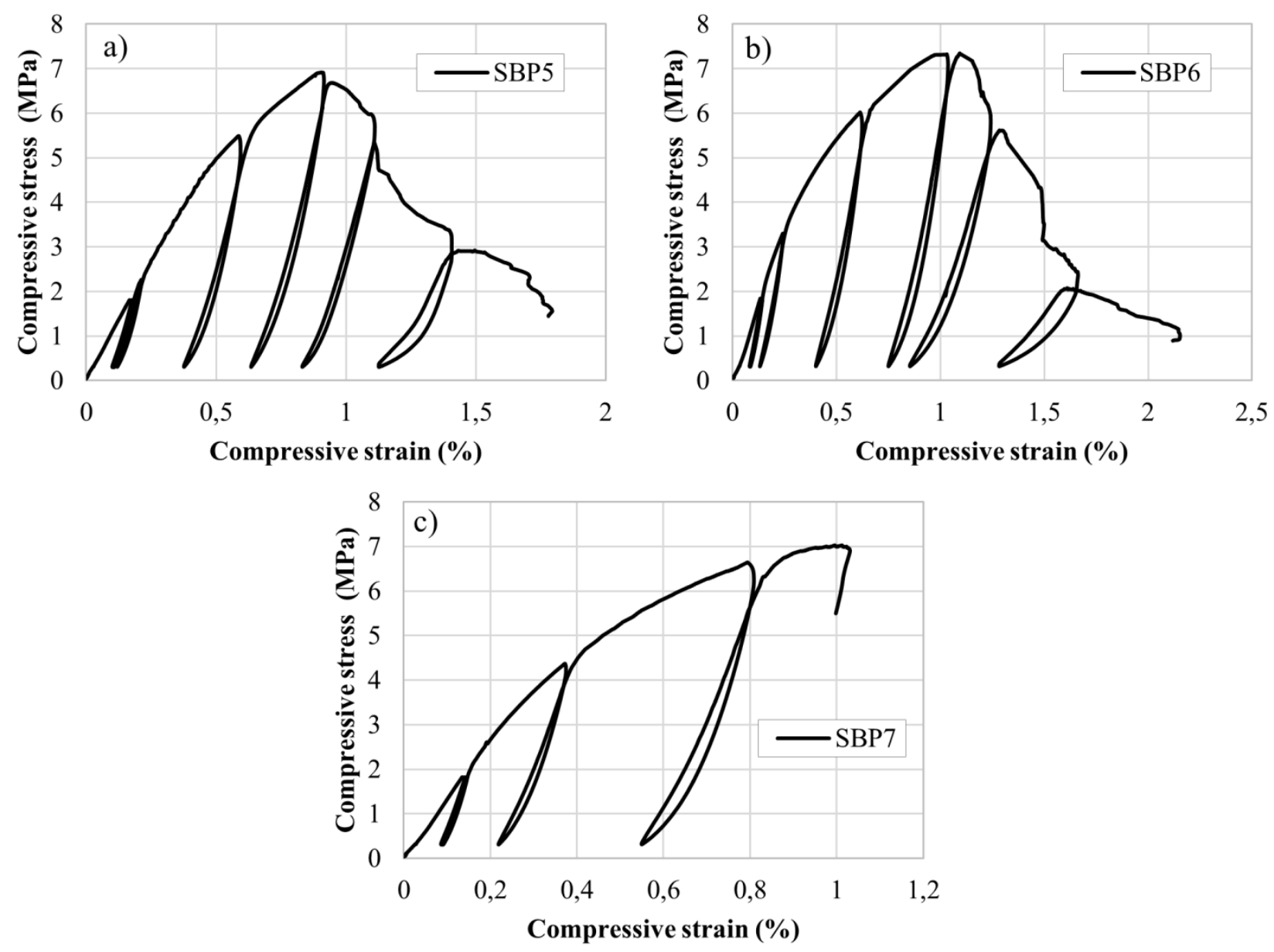

Fig. 9. Stress vs. strain experimental curves of the stack bond prisms with cyclic loading until failure. a) SBP5, b) SBP6,

c) SBP7.

The displayed curves clearly reveal the non-linear behaviour, the accumulation of non-reversible strains and the stiffness degradation experienced by masonry under cyclic loading. As stated by former researches $[7,25,27,41]$, the cyclic behaviour is characterized by the presence of intersecting points between the reloading branches and the unloading branches of previous cycles, the so-called 'common points'. In the tests here presented, the reloading branches are almost straight lines for cycles before the peak load, while after the peak load they present a more complex shape. This is consistent with the findings of similar experimental campaigns, e.g. Naraine et al. [41].

One important feature shown by the experimental curves is the stiffness degradation experienced at each cycle, which is accentuated after the peak load. Fig. 10 illustrates the evolution of the elastic 
modulus as a function of strain by means of normalized values. The normalized elastic modulus is calculated as the ratio between the elastic modulus of each reloading branch $\left(E_{c, i}\right)$ and the maximum elastic modulus found for that specimen $\left(E_{c, \max }\right)$. The normalized compressive strain used here for each reloading branch is the ratio between the strain at the end of the branch $\left(\varepsilon_{r, i}\right)$ and the strain at peak stress $\left(\varepsilon_{p}\right)$ reported in Table 4. As can be observed, values of $E_{c}$ are maximum and almost constant for the first cycles, corresponding to strains below $25 \%$ of the strain at peak stress. At peak stress, the stiffness degradation attains 20 to $40 \%$ of the initial one. After the peak load, the decrease of the elastic modulus is very significant due to the damage experienced by the material.

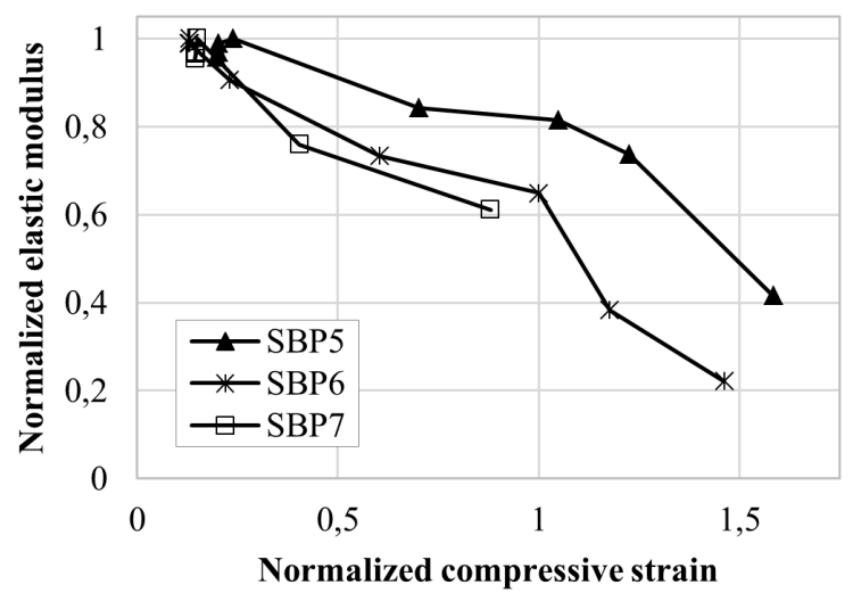

Fig. 10. Normalized elastic modulus $\left(E_{c, i} / E_{c, \max }\right)$ of the reloading branches vs. normalized compressive strain $\left(\varepsilon_{r, i} / \varepsilon_{p}\right)$, for the stack bond prisms tested under cyclic loading.

The crack patterns and mechanical behaviour of the prisms under cyclic loading were essentially the same as the ones reported for the monotonically loaded prisms in section 3.2. The resulting experimental values are included in Table 4 and are characterized by an average elastic modulus of $2380 \mathrm{MPa}$, compressive strength of $6.95 \mathrm{MPa}$, and strain at peak stress of $1.0 \%$.

Additionally, an estimation of the compressive fracture energy $\left(G_{f c}\right)$ could be done for specimens SBP5 and SBP6 since their post-peak response was captured until low values of residual load. It was calculated as the area below the envelope stress-displacement curve through a Riemann sum. Results are $8700 \mathrm{~N} / \mathrm{m}$ for SBP5 and $10800 \mathrm{~N} / \mathrm{m}$ for SBP6. 


\section{Analytical studies}

The aim of this section is to investigate the validity of existing predictive equations and models for the estimation of the compressive strength and the elastic modulus of masonry and the simulation of its compressive behaviour. The experimental results are compared with analytical and empirical expressions.

\subsection{Masonry compressive strength}

In the absence of experimental evidence obtained through standardized tests, such as the ones described in EN 1052-1 [12] or ASTM C1314-09 [13], building codes propose the use of some expressions for the determination of the masonry compressive strength from the properties of the component materials. Eurocode 6 [42] allows the use of an equation (Appendix. Eq. A1) that relates the characteristic compressive strength of masonry with the compressive strengths of brick and mortar. Similarly, the American ACI, ASTM and TMS, on a Commentary on the Specification for Masonry Structures ACI 530.1-02 [43], proposes the use of an empirical expression (Appendix. Eq. A2) that relates the compressive strength of masonry to the compressive strength of the units only.

Several authors have derived analytical models or closed form expressions to estimate the compressive strength of masonry. Among others, Hilsdorf [44], Khoo \& Hendry [45], and Ohler [46], developed models based on equilibrium and the multiaxial stress states experienced by the masonry components at failure. The proposed formulations (Appendix. Eq. A3 to A5) depend on the relative thicknesses of the components, the compressive strength of mortar, and both the compressive and tensile strength of the units. The reader is referred to [10,47] for details about these models and the standards’ expressions.

The compressive strength of masonry was evaluated for the different equations aforementioned. A specific investigation has been carried out on the sensitivity of the models to the variation of the 
material properties. For that purpose, a virtual sample of data normally distributed was created for each of the material properties reported in Table 1 and Table 2. The tensile strength of the bricks was determined from the bending tensile one by applying the conversion formula proposed by Eurocode 2 [48]. This formula (Appendix. Eq. A6) was used in the lack of a more specific one available for clay bricks. Each virtual sample was composed of 5000 data and characterized by the mean and the standard deviation of each property. 5000 strength estimations were obtained for each equation. A summary of the results indicating the mean value and the coefficient of variation is shown in Table $\mathbf{5}$. All the predictions can be compared with the average experimental values $\left(f_{c, \exp }\right)$. To convert the characteristic value provided by the European code [42] to the average one, the former was multiplied by a factor equal to 1.2 as proposed by the EN 1052-1 [12]. In the table, $f_{c, E C 6}$ and $f_{c, A C I}$ refer to the values calculated with Eurocode 6 [42] or ACI 530.1-02 [43], while $f_{c, H i l s d o r f, ~} f_{c, K \& H}$ and $f_{c, \text { Ohler }}$ correspond to those calculated according to [44], [45] and [46] respectively. All the analytical predictions present reasonable estimations of the compressive strength of masonry, being $f_{c, E C G}$ and $f_{c, K \& H}$ the lower and upper bounds respectively.

Table 5. Experimental and analytical compressive strength values (MPa). The coefficient of variation is indicated in brackets.

\begin{tabular}{ccccccc}
\hline Sample & $f_{c, \exp }$ & $f_{c, \text { EC6 }}$ & $f_{c, \text { ACI }}$ & $f_{c, \text { Hilsdorf }}$ & $f_{c, \text { K\&H }}$ & $f_{c, \text { Ohler }}$ \\
\hline RBW & $6,51(8.9 \%)$ & & & & & \\
SBP,mono & $6,49(9.1 \%)$ & $6,06(6.7 \%)$ & $6,36(4.8 \%)$ & $6,80(9.3 \%)$ & $7,14(10.0 \%)$ & $6,47(9.8 \%)$ \\
SBP,cyclic & $7,1(3.1 \%)$ & & & & & \\
\hline
\end{tabular}

\subsection{Masonry stiffness}

In the case of the elastic modulus of masonry, building codes also propose some simple relationships to estimate this parameter in the lack of experimental results. Eurocode 6 [42] proposes to evaluate the elastic modulus $\left(E_{c, E C 6}\right)$ through a linear relationship with the masonry characteristic compressive strength. The recommended constant of proportionality is 1000. The American Requirements for Masonry Structures [49] follow a similar approach and suggest to estimate the elastic modulus $\left(E_{c, A C I}\right)$ as 700 times the compressive strength. These criteria were applied to the masonry 
herein investigated by using the strength estimates obtained in the previous section 4.1. The comparison with the experimental results $\left(E_{c, \text { exp }}\right)$ is included in Table 6. The experimental value shown for the SBPs is an average of all the static and cyclic tests on prisms (7 tests) since they do not differ in the procedure used for the measurement of the elastic modulus.

Based on the findings of Pande et al. [50], Pelà et al. [39] proposed a very simple one-dimensional homogenization method for the estimation of the elastic modulus of masonry. This model considers the interaction of units with bed and head mortar joints as a system of series-parallel uniaxial springs, by incorporating the elastic moduli of the material components. It allows using different expressions for the different testing specimens such as stack bond prisms -without head joints-, and running bond walls -with head joints. The model (Appendix. Eq. A7 and A8) was applied with the material properties specified in Table 1 and Table 2. In the lack of a specific measurement, the elastic modulus of the bricks in the direction parallel to the load was estimated as the average of the values of the other two perpendicular directions. Table 6 presents the results of the homogenization method $\left(E_{c, 1 D}\right)$ that provides more accurate Young's moduli estimations than the expressions provided by the aforementioned standards.

Table 6. Experimental and analytical elastic modulus values (MPa).

\begin{tabular}{ccccc}
\hline Sample & $E_{c, \exp }$ & $E_{c, 1 D}$ & $E_{c, E C 6}$ & $E_{c, A C I}$ \\
\hline RBW & 2318 & 2075 & \multirow{2}{*}{5050} & \multirow{2}{*}{4445} \\
SBP, all & 2445 & 2098 & & \\
\hline
\end{tabular}

\subsection{Stress-strain relationships under cyclic loading}

The literature review presented in section 1 reported a limited number of references dealing with the experimental testing of masonry under cyclic compression. The number of references studying the constitutive stress-strain laws of the masonry cyclic compressive response is even more reduced. Naraine \& Sinha [41] proposed a simple mathematical model to predict the unloading and reloading curves of brick masonry. It consisted of exponential stress-strain relationships, which were calibrated to fit previous experimental data obtained by them [25]. The same data were used by Eibl et al. [51] to 
define another simple model, which proposed exponential unloading curves and linear reloading curves. Similar formulations, representing the curves with exponential or polynomial functions are also included in [52-54] for different types of masonry. None of the former models considered the case of partial unloading-reloading.

Sima et al. [55] proposed a more complex constitutive model based on a damage parameter. The model was also calibrated using experimental results of Naraine and Sinha [25]. The newest available approach is the one formulated by Facconi et al. [28], which is partially based on the work of Crisafulli [56]. Its equations were calibrated for different types of masonry tested by different authors $[7,25,28,53,57,58]$.

The latter two models are able to also predict the case of partial unloading-full reloading. In addition to their larger generality, these two models have been selected for the present investigation because of their ability to model cyclic loading processes not reaching zero stress as in the case of the experiments presented in section 3.3.

The two investigated models consider the strain at the onset of unloading as the internal variable that completely defines a whole cycle of unloading-reloading. The rest of parameters controlling the cycle are obtained from this strain by means of relationships adjusted from experimental data. The parameters of the model of Sima et al. [55] have been recalibrated in this work by using the experimental results of tests SBP5, SBP6 and SBP7 as reference data. The new calibration is displayed in Fig. 13 in terms of relationships between unloading strain to plastic strain ratio $(r)$ and the unloading damage $\left(\delta_{u n}\right)$, between the final unloading stiffness to initial stiffness ratio $(R)$ and the unloading damage $\left(\delta_{u n}\right)$, and between the reloading damage $\left(\delta_{r e}\right)$ and the unloading damage $\left(\delta_{u n}\right)$.

The model of Sima et al. [55] defines the envelope curve based on the modulus of the initial linear branch $\left(E_{o}\right)$, the strain value limiting the initial branch $\left(\varepsilon_{o}\right)$, the compressive strength $\left(f_{c}\right)$ and the strain at the peak stress $\left(\varepsilon_{p}\right)$. The model of Facconi et al. [28] considers the same parameters with the 
exception of the strain limiting the initial branch. Instead, their model uses the ultimate strain at zero stress $\left(\varepsilon_{u}\right)$ to also delimit the post-peak response.

In both cases, unloading branches are defined via nonlinear equations. Sima et al. [55] proposes straight reloading branches. Conversely, Facconi et al. [28] implements a more refined doublecurvature law for the reloading response, although the limits of the resulting curves are also based on a linear relationship. In addition, the model of Facconi et al. offers the possibility to modify the value of some parameters to obtain a better adjustment of the curves and specifically the parameter $\gamma_{u n}$, which governs the initial slope of the unloading curves.

Both models have been used to simulate the tests on specimens SBP5 and SBP6, with the input data indicated in Table 7. Fig. 11a and Fig. 12a show the comparison between the experimental stressstrain curves of specimens SBP5 and SBP6, respectively, and the analytical curves obtained through the direct application of Facconi et al. model [28]. Fig. 11b and Fig. 12b display the comparison with the model of Sima et al. [55] with the new calibration previously indicated.

Table 7. Model input data for comparison with the experimental results of specimens SBP5 and SBP6.

\begin{tabular}{cccccccc}
\hline Specimen & Model & $E_{o}(\mathrm{MPa})$ & $\varepsilon_{o}(\%)$ & $f_{c}(\mathrm{MPa})$ & $\varepsilon_{p}(\%)$ & $\varepsilon_{u}(\%)$ & $\gamma_{u n}(-)$ \\
\hline \multirow{2}{*}{ SBP 5 } & Facconi et al. [28] & 1100 & - & 6.91 & 0.90 & 1.60 & 3 \\
& Sima et al. [55] & 1030 & 0.5 & 6.91 & 0.90 & - & - \\
\hline \multirow{2}{*}{ SBP 6 } & Facconi et al. [28] & 1600 & - & 7.34 & 1.09 & 2.00 & 3 \\
& Sima et al. [55] & 1463 & 0.2 & 7.34 & 1.09 & - & - \\
\hline
\end{tabular}



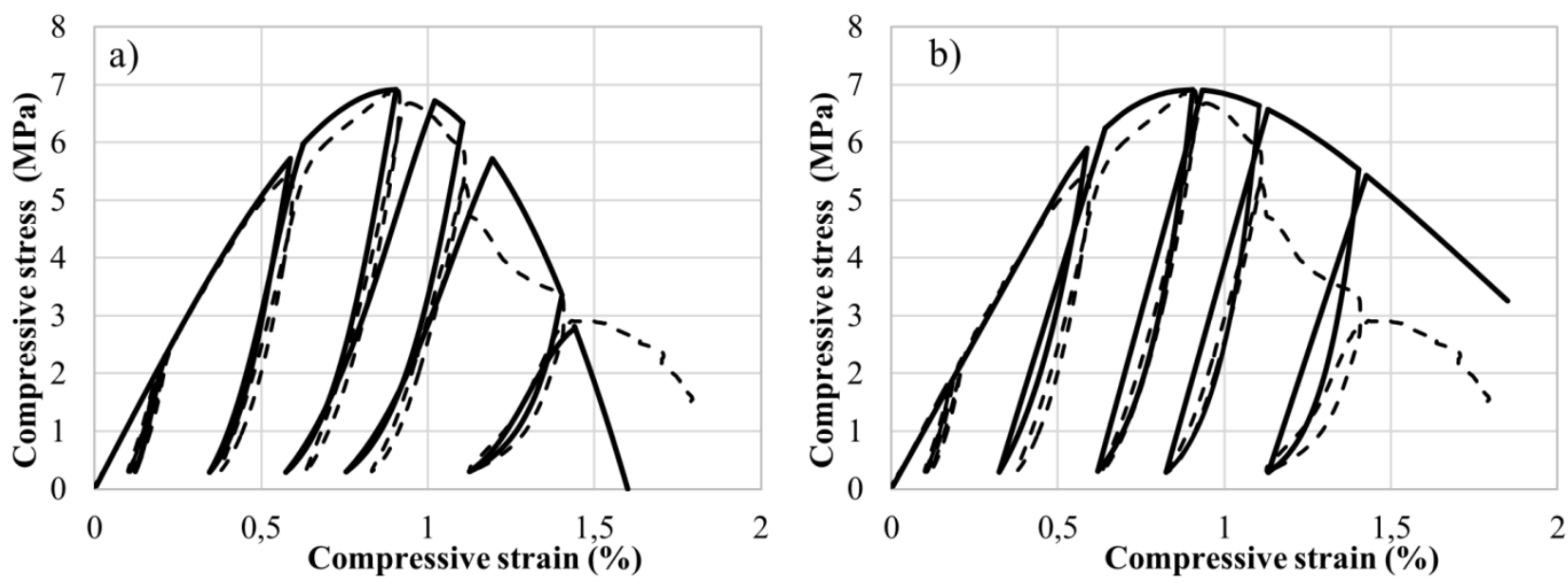

Fig. 11. Experimental (dashed) and analytical (solid) stress-strain curves for specimen SBP5. a) Analytical model by Facconi et al. [28], b) Analytical model by Sima et al. [55], with new calibration.
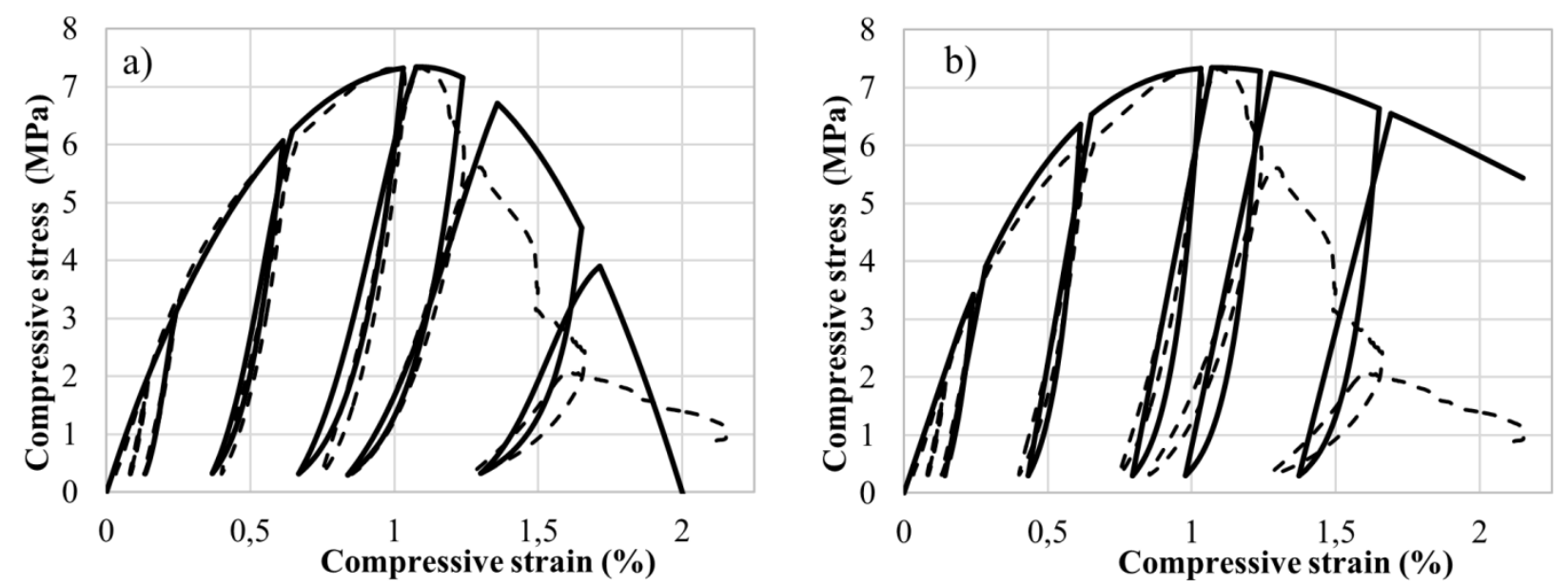

Fig. 12. Experimental (dashed) and analytical (solid) stress-strain curves for specimen SBP6. a) Analytical model by Facconi et al. [28], b) Analytical model by Sima et al. [55], with new calibration. 

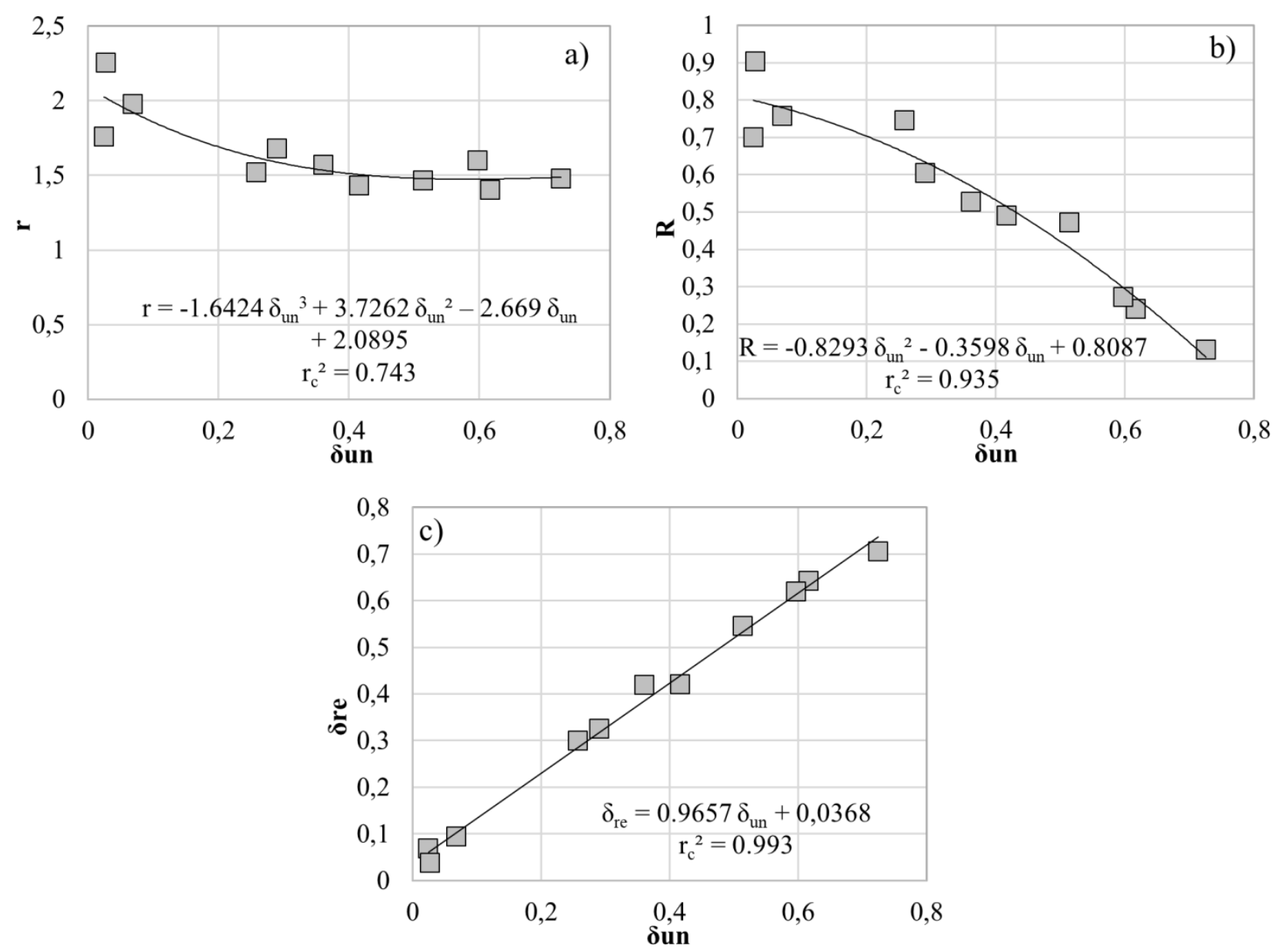

Fig. 13. New relationships for the model proposed by Sima et al. [55], obtained by curve fitting of the present work's experimental data. Notation according to [55]. a) Relationship between unloading strain - plastic strain ratio $(r)$ and the unloading damage $\left(\delta_{u n}\right)$, b) Relationship between the final unloading stiffness - initial stiffness ratio $(R)$ and the unloading damage $\left(\delta_{u n}\right)$, c) Relationship between the reloading damage $\left(\delta_{r e}\right)$ and the unloading damage $\left(\delta_{\text {un }}\right)$. In the above, $\mathrm{r}_{\mathrm{c}}{ }^{2}$ is the coefficient of determination $\mathrm{R}$ squared.

\section{Discussion}

Masonry specimens of two different configurations, consisting in running bond walls (RBWs) built according to EN 1052-1 [12] and stack bond prisms (SBPs) built following ASTM C1314 [13], have been tested under uniaxial compression. The failure modes observed during the tests have been very similar for both sets of samples. The response of both types of specimen was characterized by an initial crack pattern consisting of thin vertical cracks in the bricks, appearing mainly near the specimens' edges. With the increase of load, these cracks become later apparent across the mortar 
joints and propagated over the whole height of the specimens. Additional vertical cracks affected the central part of the faces after the peak load. A final remaining core was observed showing a sandglass shape, as typically obtained in compression tests. Due to their similar failure mode, both types of sample can be considered able to represent the complex mechanism of the compressive response of masonry.

The average value of the compressive strength obtained for stack bond prisms tested under cyclic loading is 7.10 MPa, which is slightly higher than the strength obtained for monotonically loaded prisms, equal to $6.49 \mathrm{MPa}$. The associated variabilities, the scattering of the materials (see Table $\mathbf{1}$ and Table 2), and the limited amount of specimens tested might justify such a difference derived from monotonic and cyclic testing. The monotonic curves seem to provide, however, a good estimate of the peaks’ envelope of cyclic curves, as also seen by [7,25,27].

The strength obtained for the stack bond prisms is very similar to that obtained for the running bond walls, equal to 6.51 MPa. The difference is very small and may be only due to the scattering of the material properties. The almost null influence of the head joints in the wall specimens may be explained as the consequence of a careful construction in laboratory involving the accurate filling of all joints with mortar. It should be noted that the presence of head joints could have a more detrimental effect in not-so-carefully built masonries.

Very moderate coefficients of variation, of 9.1\% for SBP under monotonic load, 3.1\% for SBP under cyclic load and 8.9\% for RBW, have been obtained. These coefficients are lower than the ones obtained for the material properties. It can be said that, as shown in the experiments, the scattering of the results on composite specimens is smaller than that shown by the component materials.

The equations available in the standards for the prediction of the compressive strength have provided satisfactory estimations of the strengths measured experimentally, as reported in Table 5. In the case of the ACI equation [43], a satisfactory estimation has been obtained in spite of the fact that it was originally adjusted for more resistant masonry types than the one studied herein [43]. 
Table 5 also includes the results of the application of three closed form expressions to predict the compressive strength. The three equations yield very accurate values fully comprised within the limits of the experimental ones taking into account the obtained scattering. Nevertheless, former researches such as [39,47] have found that these formulas may in some cases overestimate the experimental strength. A possible explanation for this overestimation can be found in the fact that the three equations, based on equilibrium considerations, are very sensitive to the value of the tensile strength of the units. The latter is a mechanical parameter of difficult determination whose measurement is not covered by any available standard. Due to it, these equations or similar closed form ones should only be used when reliable values of the material properties have been made available through accurate experimental tests.

Table 5 also presents the coefficients of variation obtained for the simulations. In a way consistent with the experimental results, the 5 studied equations provide coefficients of variation lower than the ones of the component material properties.

The elastic modulus of masonry has been evaluated as the chord modulus of the stress-strain curves between the $5 \%$ and $30 \%$ of the maximum compressive load obtained after three initial loading cycles. The execution of the cycles is done, among other reasons, to cancel possible effects related to the first contact between the specimens and the loading machine platens. As shown in Fig. 5a and Fig. 7a, and highlighted in [30], the performance of cycles introduces irreversible strains in the specimen, which leads to an increase in the stiffness of the reloading branches. In addition to the platen-specimen contact effects, these irreversible strains might be due to an initial compaction of the material motivated by the closing of micro-cracks in the unit-mortar interface and voids within the mortar joints [20]. The elastic moduli computed following this approach, after the application of cycles, are considered to be more realistic than the very low ones that would be obtained from the initial curves.

A very similar value of the elastic modulus has been obtained for both types of specimen (RBW and SBP), with a difference of only 5\%. The average elastic modulus obtained for running bond walls 
is $2318 \mathrm{MPa}$, while for all stack bond prisms is $2445 \mathrm{MPa}$. The latter value has been obtained as an average for the 7 SBPs, since there is no difference between monotonic and cyclic tests at this test stage. The similitude of the values for both specimen types was expected since the LVDTs were placed considering the same reference lengths, which included two bed joints and one full brick.

The small difference between the elastic modulus obtained in the two specimen types may be explained as due to the scattering of the material properties. It might be also explained by the presence of the head joint in the case of the RBWs. In fact, the applied spring model detects a certain influence of the head joint, as shown by the results included in Table 6 for the simple 1-D homogenization, with a slightly lower value for the case of RBWs. In both cases, this simple method has provided a very satisfactory estimation of the experimental values. The relative errors, from $-10 \%$ to $-15 \%$, are of the same magnitude of those found by [39]. However, it is worth mentioning that this method is based on mechanical parameters (the elastic modulus of both units and mortar) that are difficult to be accurately measured in laboratory.

Compared to the compressive strengths, $E_{c} / f_{c}$ ratios equal to 356 and 362 are obtained respectively for running bond walls and stack bond prisms. The ratios proposed by the building codes, equal to 1000 in the case of the European Eurocode 6 [42] and to 700 in the American requirements [49], clearly overestimate the measured elastic modulus. This provides further evidence on the fact that these expressions, derived mainly for new masonry, don’t apply for historical or existing masonry made of solid clay bricks and lime mortar. Previous researches on clay brick masonry have also obtained $E_{c} / f_{c}$ ratios significantly below those indicated by the codes, as for instance [59] with a ratio of 550, [60] with a ratio of 422 , or the inventory presented in [10] with an average ratio of 356 . In any case, the ratios obtained herein are very similar for both types of specimen. Additionally, the coefficients of variation associated to the estimation of the elastic modulus are moderately low ( $7.6 \%$ for RBWs, and 8.8\% and $15.5 \%$ for SBPs). The performance of initial load cycles during the tests may have contributed to reduce the scattering obtained in the measurement of this mechanical property. 
A much higher scattering, with a variation coefficient between $9.4 \%$ for stack bond prisms under cyclic loading and 37.6\% for running bond walls, has been obtained for the values of the strain at peak stress. However, the average values attained for the different samples are similar and equal to $1.2 \%$ and $1 \%$ for SBPs tested monotonically and cyclically respectively and to $0.98 \%$ for RBWs. The strain at peak stress shows a strong dependence on the compressive strength, and tends to decrease as the strength increases.

In the case of the cyclic tests performed on stack bond prisms it has been possible to record the evolution of stiffness along the full tests and its progressive reduction with the accumulation of damage, as shown in Fig. 10. Additionally, it has been possible to capture a significant fraction of the post-peak response, as in the researches made by Oliveira et al. [23] and De Felice [30]. The tests here presented have confirmed the loss of load-carrying capacity with increasing strains, but also the ability of the specimens to resist full unloading-reloading cycles after the peak load. In tests SBP5 and SBP6 the reloading branches recovered the stresses level attained before the unloading.

Taking advantage of the almost complete curves obtained for SBP5 and SBP6 specimens, the compressive fracture energy was evaluated. Lourenço [61] introduced the concept of ductility index as the ratio between the compressive fracture energy and the compressive strength. The experimental ductility indices computed for this campaign are $1.24 \mathrm{~mm}$ for test SBP5 and $1.47 \mathrm{~mm}$ for test SBP6. These values are close to the recommendation of $1.6 \mathrm{~mm}$ found in literature [61] for masonry with compressive strength lower than $12 \mathrm{MPa}$.

The two cyclic constitutive models studied are in good agreement with the experimental results obtained for specimens SBP5 and SBP6. Sima et al. model [55] is simpler and requires a lesser number of input parameters. However, in order to obtain a satisfactory agreement with the experimental results it has been necessary to recalibrate the parameters of the model based on the current tests. Conversely, Facconi et al. [28] model has provided a satisfactory agreement by directly applying the parameter values originally recommended by the authors, which were adjusted based on a set of different 
experimental campaigns. Compared to Sima et al model [46], the envelope curve formulated by Facconi et al. [28] has provided a better fit to the test results. The nonlinear shape proposed for the reloading branches is also more realistic. The prediction of the intersection of the reloading branches with the envelope curve for post-peak cycles, however, could be improved with an expanded series of experimental results.

\section{Conclusions}

This paper has presented an experimental programme with new insights on the mechanical behaviour of brick masonry under compression. Two different sets of specimens were tested consisting of running bond walls built according to the geometric prescriptions of EN 1052-1 and stack bond prisms built according to ASTM C1314. They were tested in the laboratory under uniaxial compression to evaluate their compressive strength, elastic modulus and post-peak behaviour. A set of three stack bond prisms was tested under cyclic loading. The following conclusions can be drawn from these experiments:

- For the specific combination of materials studied, the tests on the two types of standard specimens have provided similar results in terms of compressive strength and deformability. Additional research should be carried out to extend this conclusion to other types of masonry.

- New experimental evidence on the behaviour of masonry under uniaxial cyclic loading has been obtained. Consistently with previous researches, the tests have shown the stiffness degradation of masonry for increasing strains. They have also shown that the static strain-stress curves can be used as a satisfactory estimation of the peak envelope of cyclic tests.

- The evaluation of the elastic modulus of masonry has been done after the application of three initial loading-unloading cycles. This approach is consistent with the recommendations of standards on other materials specifically devoted to the determination of this parameter. Given 
the consistency of the experimental results obtained herein, it is recommended to measure the elastic modulus of masonry, as a general rule, after the application of several cycles.

- The expressions provided by the European and American standards and some authors for the evaluation of the compressive strength of masonry have provided values in agreement with the experimental ones. Conversely, the criteria proposed by these standards for the calculation of elastic modulus have strongly overestimated the experimental corresponding values. The elastic modulus has been satisfactorily estimated, however, by means of a simple onedimensional homogenization model. Two cyclic constitutive models investigated, proposed by different authors, have shown their ability to satisfactorily simulate the cyclic response obtained in the experimental tests. As opposite to Facconi et al. model, the use of Sima et al. model has required significant previous calibration.

\section{Acknowledgements}

The authors gratefully acknowledge the financial support from the MINECO (Ministerio de Economía y Competitividad of the Spanish Government) and the ERDF (European Regional Development Fund) through the MULTIMAS project (Multiscale techniques for the experimental and numerical analysis of the reliability of masonry structures, ref. num. BIA2015-63882-P). Support from Secretaria d’Universitats i Investigació de la Generalitat de Catalunya through a predoctoral grant awarded to the first author is also gratefully acknowledged.

The authors wish to thank Diego Aponte for his helpful contribution to the mortar design, and Paolo Casadei and Patricio Contreras from KERAKOLL S.p.A. for providing the mortar materials used in the experimental campaign.

\section{Appendix: Equations used in Section 4. Analytical studies}

\section{Masonry compressive strength}


The equation proposed by Eurocode 6 [42] is

$$
f_{c, k}=K f_{b, c}^{0.7} f_{m, c}^{0.3}
$$

where $f_{c, k}(\mathrm{MPa})$ is the characteristic compressive strength of the masonry, $f_{b, c}(\mathrm{MPa})$ is the normalised mean compressive strength of the units, $f_{m, c}(\mathrm{MPa})$ is the compressive strength of the mortar and $K, \alpha$, $\beta$ are constants. For the case studied herein, masonry made with general purpose mortar and solid clay units, the values of these constants are $0.55,0.7$ and 0.3 respectively.

The equation proposed in the Commentary on Specification for Masonry Structures (ACI 530.102/ASCE 6-02/TMS 602-02) [43] for clay brick masonry is

$$
f_{c, A C I}=A\left(400+B f_{b, c}\right)
$$

where $f_{c, A C I}$ is the specified compressive strength of masonry (psi), $f_{b, c}$ is the average compressive strength of brick (psi), $A$ and $B$ are constants. $A$ is equal to 1 for inspected masonry and $B$ is equal to 0.2 for Type $\mathrm{N}$ mortar.

The equation proposed by Hilsdorf [44] is

$$
f_{c, \text { Hilsdorf }}=\frac{f_{b, c}}{U_{u}} \frac{f_{b, t}+\mu f_{m, c}}{f_{b, t}+\mu f_{b, c}}
$$

in the above, $f_{c, H i s l d o r f}$ is the compressive strength of masonry, $f_{b, t}$ is the tensile strength of brick (MPa), $f_{b, c}$ is the compressive strength of brick (MPa) and $f_{m, c}$ is the compressive strength of mortar (MPa). $\mu$ is a geometric factor relating the mortar joint thickness to brick height $\left(\mu=h_{m} /\left(4.1 h_{b}\right)\right)$. $U_{u}$ is a nonuniformity coefficient at failure. In this research, its value has been taken as 1.5.

The equation proposed by Khoo and Hendry [45] is

$$
A f_{C, K \& H}^{3}+B f_{C, K \& H}^{2}+C f_{c, K \& H}+D=0
$$

where $f_{c, K \& H}$ is the compressive strength of masonry (MPa) and the parameters $A, B, C$ and $D$ are computed as 


$$
\begin{aligned}
& A=-0.2487 f_{b, t}\left(\frac{1}{f_{b, c}}\right)^{3}+0.0018 \delta\left(\frac{1}{f_{m, c}}\right)^{2} \\
& B=1.2781 f_{b, t}\left(\frac{1}{f_{b, c}}\right)^{2}-0.0529 \delta\left(\frac{1}{f_{m, c}}\right) \\
& C=-2.0264 f_{b, t}\left(\frac{1}{f_{b, c}}\right)-0.1126 \delta \\
& D=0.9968 f_{b, t}+0.1620 \delta f_{m, c}
\end{aligned}
$$

in the above, $f_{b, t}$ is the tensile strength of brick (MPa), $f_{b, c}$ is the compressive strength of brick (MPa) and $f_{m, c}$ is the compressive strength of mortar (MPa). $\delta$ is a geometric factor equal to the ratio of the mortar joint thickness to brick height $\left(\delta=h_{m} / h_{b}\right)$.

The equation proposed by Ohler [46] is

$$
f_{c, \text { ohler }}=f_{m, c}+\frac{s f_{b, c}-f_{m, c}}{1+\frac{t h_{m} f_{b, c}}{m h_{b} f_{b, t}}}
$$

where $f_{c, \text { Ohler }}$ is the compressive strength of masonry (MPa), $f_{b, t}$ is the tensile strength of brick (MPa), $f_{b, c}$ is the compressive strength of brick (MPa) and $f_{m, c}$ is the compressive strength of mortar (MPa). $h_{m}$ is the mortar joint thickness and $h_{b}$ is the brick height. $s$ and $t$ are parameters defining the brick failure envelope and $m$ is the slope of the mortar failure envelope [47].

\section{Flexural to tensile strength relationship}

The equation provided by Eurocode 2 [48] that relates the flexural and tensile strengths of concrete is

$$
f_{c t m}=\frac{f_{c t m, f l}}{\left(1.6-\frac{h}{1000}\right)}
$$

where $f_{c t m}$ is the tensile strength of concrete, $f_{c t m, f l}$ is the flexural strength of concrete and $h$ is the height of the element in mm. In the lack of a specific expression for bricks, it has been used herein with the tensile strength of brick $f_{b, t}$ and the flexural strength of brick $f_{b, f l}$. 


\section{Masonry stiffness}

The equation of the simple one-dimensional homogenization model for the stack bond prisms is

$$
E_{1 D}=\frac{l_{r e f}}{\frac{h_{b, 1}}{E_{b}}+\frac{h_{m, 1}}{E_{m}}+\frac{h_{b, 2}}{E_{b}}+\frac{h_{m, 2}}{E_{m}}+\frac{h_{b, 3}}{E_{b}}}
$$

where $E_{1 D}$ is the equivalent elastic modulus of masonry, $E_{b}$ is the elastic modulus of brick and $E_{m}$ is the elastic modulus of mortar. The expression applies to the specific geometry of this test and the reference length $\left(l_{r e f}\right)$ measured by the LVDTs (Fig. A1). $h_{b, i}$ is the height of the $i$ brick portion and $h_{m, i}$ is the thickness of the $i$ mortar joint.

In the case of the running bond walls, the middle term of the denominator incorporates the influence of the mortar head joint

$$
E_{1 D}=\frac{l_{r e f}}{\frac{h_{b, 1}}{E_{b}}+\frac{h_{m, 1}}{E_{m}}+\frac{h_{b, 2} * t}{E_{b} *\left(t_{b 1}+t_{b 2}\right)+E_{m} * t_{m}}+\frac{h_{m, 2}}{E_{m}}+\frac{h_{b, 3}}{E_{b}}}
$$

where $t$ is the total contributing width considered in the computation, $t_{b}$ is the width of the bricks and $t_{m}$ is the width of the mortar head joint. 

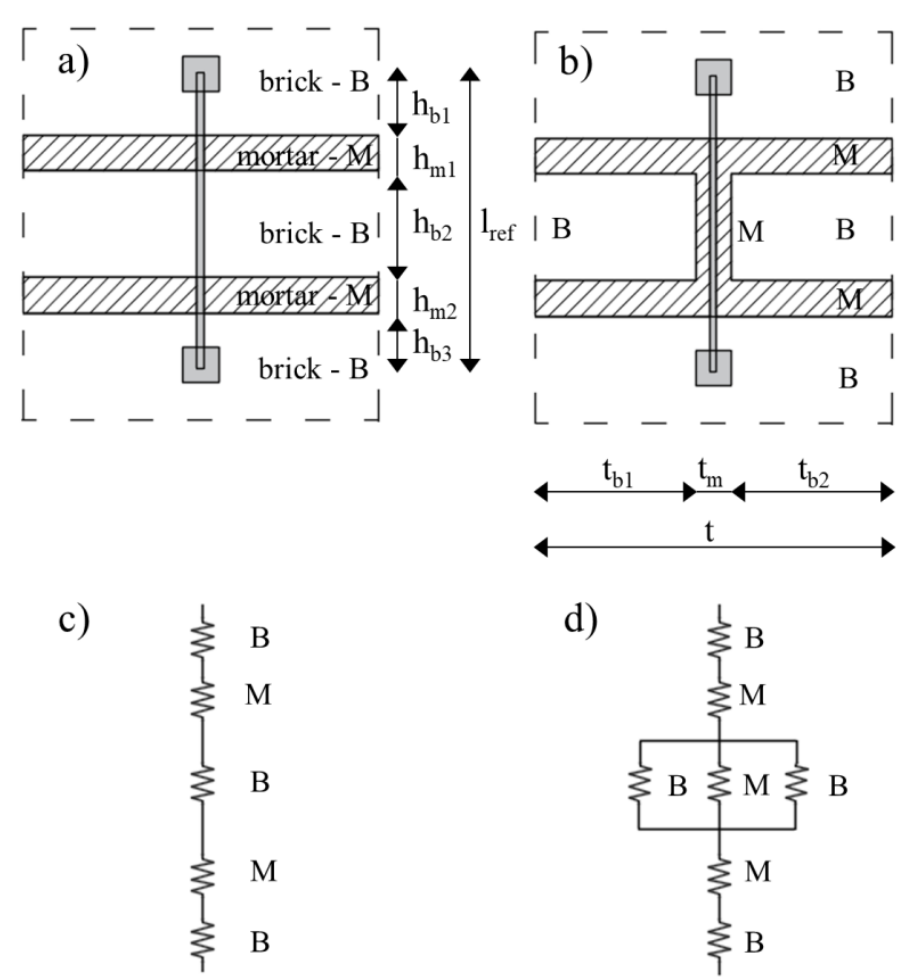

Fig. A.1. One-dimensional homogenization model for elastic modulus estimation. a) and b) Sketches of the portions of specimen being measured by the LVDTs for stack bond prisms and running bond walls respectively. c) and d) Representation by spring-like elements of the simplified models for stack bond prisms and running bond walls respectively.

\section{References}

[1] A.W. Hendry, B.P. Sinha, S.R. Davies, Design of masonry structures, 3rd ed., Taylor \& Francis, 2004.

[2] P.B. Lourenco, Masonry structures, overview, in: Encycl. Earthq. Eng., Springer-Verlag Berlin Heidelberg, 2014: pp. 1-9. doi:10.1007/978-3-642-36197-5_111-1.

[3] P.B. Lourenço, F. Fernandes, F. Castro, Handmade clay bricks: chemical, physical and mechanical properties., Int. J. Archit. Herit. 4 (2009) 38-58.

[4] G. López-Patiño, J.M. Adam, P. Verdejo Gimeno, G. Milani, Causes of damage to industrial brick masonry chimneys, Eng. Fail. Anal. 74 (2017) 188-201. doi:10.1016/j.engfailanal.2017.01.014.

[5] A.P. Russell, J.M. Ingham, Prevalence of New Zealand’s Unreinforced Masonry Buildings, Bull. New Zeal. Soc. Earthq. Eng. 43 (2010) 182-202.

[6] L.S. Hogan, I. Giongo, K.Q. Walsh, J.M. Ingham, D. Dizhur, Full-scale Experimental Pushover Testing of an Existing URM Building, Structures. 15 (2018) 66-81. doi:10.1016/j.istruc.2018.04.007.

[7] M. Ispir, A. Ilki, Behavior of Historical Unreinforced Brick Masonry Walls under Monotonic and Cyclic 
Compression, Arab. J. Sci. Eng. 38 (2013) 1993-2007. doi:10.1007/s13369-013-0567-4.

[8] A. Amirzadeh, R.K. Strand, R.E. Hammann, M.S. Bhandari, Determination and Assessment of Optimum Internal Thermal Insulation for Masonry Walls in Historic Multifamily Buildings, J. Archit. Eng. 24 (2018) 1-12. doi:10.1061/(ASCE)AE.1943-5568.0000320.

[9] D. Liberatore, A. Marotta, L. Sorrentino, Estimation of solid clay brick unreinforced masonry compressive strength based on mortar and unit mechanical parameters, in: Proceedigns of 9th Int. Mason. Conf., Guimaraes, 2014: pp. 1715-1722.

[10] A. Drougkas, C. Molins, P. Roca, Numerical prediction of the behavior, strength and elasticity of masonry in compression, Eng. Struct. 90 (2015) 15-28. doi:10.1016/j.engstruct.2015.02.011.

[11] D. Ferretti, E. Coïsson, D. Ugolotti, E. Lenticchia, Use of EC6-like equations to estimate the compressive strength of masonry made of solid clay bricks and lime mortar, in: C. Modena, F. da Porto, M.R. Valluzzi (Eds.), Brick Block Mason. - Trends, Innov. Challenges, Taylor \& Francis Group, London, 2016: pp. 1561-1570.

[12] European Committee for Standardization (CEN), EN 1052-1: Methods of test for masonry - Part 1: Determination of compressive strength, (1999).

[13] American Society for Testing and Materials, ASTM C1314-09 Standard Test Method for Compressive Strength of Masonry Prisms, (2009).

[14] RILEM, TC76-LUMB1 Compressive strength of small walls and prisms, (1991).

[15] S.G. Fattal, L.E. Cattaneo, Structural performance of masonry walls under compression and flexure, The National Bureau of Standards, 1976.

[16] A.T. Vermeltfoort, Compression properties of masonry and its components, in: N.G. Shrive, A. Huizer (Eds.), Proceedings of 10th Int. Brick/Block Mason. Conf., Calgary, 1994, pp. 1433-1442.

[17] L. Binda, C. Tiraboschi, G. Mirabella Roberti, Problemi di misura dei parametri meccanici della muratura e dei suoi componenti, in: Proceedings of La Mecc. Delle Murature Tra Teor. e Progett., 1996, pp. 45-54.

[18] W. Mann, M. Betzler, Investigations on the effect of different forms of tests samples to test the compressive strength of masonry, in: N.G. Shrive, A. Huizer (Eds.), Proceedings of 10th Int. Brick/Block Mason. Conf., Calgary, 1994, pp. 1305-1314.

[19] K.S. Gumaste, K.S. Nanjunda Rao, B. V Venkatarama Reddy, K.S. Jagadish, Strength and elasticity of brick masonry prisms and wallettes under compression, Mater. Struct. Constr. 40 (2007) 241-253. doi:10.1617/s11527006-9141-9.

[20] A. Drougkas, P. Roca, C. Molins, Compressive strength and elasticity of pure lime mortar masonry, Mater. Struct. 
Constr. 49(3) (2016) 983-999. doi:DOI: 10.1617/s11527-015-0553-2.

[21] G. De Casa, G. Giglio, Contributo alla conoscenza del comportamento delle murature in blocchi di tufo volcanico, in: Proceedings of 9th Int. Brick Block Mason. Conf., 1991, pp. 141-148.

[22] S. Ganduscio, L. La Mendola, G. Zingone, Comportamento ciclico di sezioni pressoinflesse in muratura, in: Proceedings of La Mecc. Delle Murature Tra Teor. e Progett., 1996, pp. 265-274.

[23] D. V. Oliveira, P.B. Lourenço, P. Roca, Cyclic behaviour of stone and brick masonry under uniaxial compressive loading, Mater. Struct. 39 (2006) 247-257. doi:10.1617/s11527-005-9050-3.

[24] M. Dhanasekar, N.G. Shrive, Strength and deformation of confined and unconfined grouted concrete masonry, ACI Struct. J. 99 (2002) 819-826.

[25] K. Naraine, S.N. Sinha, Behavior of brick masonry under cyclic compressive loading, J. Struct. Eng. 115 (1989) $1432-1445$.

[26] M.M. AlShebani, S.N. Sinha, Stress-strain characteristics of brick masonry under uniaxial cyclic loading, J. Struct. Eng. 125 (1999) 600-604.

[27] I. Galman, J. Kubica, Stress - Strain Characteristics of Brick Masonry Under Compressive Cyclic Loading, Tech. Trans. Civ. Eng. (2015). doi:10.4467/2353737XCT.15.162.4337.

[28] L. Facconi, F. Minelli, F.J. Vecchio, Predicting Uniaxial Cyclic Compressive Behavior of Brick Masonry: New Analytical Model, J. Struct. Eng. 144 (2018) 4017213. doi:10.1061/(ASCE)ST.1943-541X.0001961.

[29] R. Mattone, G. Pasero, M. Pavano, G. Pistone, R. Roccati, Prove sperimentali su campioni di varie dimensioni volte alla determinazione delle caratteristiche meccaniche delle vecchie murature, in: Proceedings of 6th Int. Brick Block Mason. Conf., 1982, pp. 198-209.

[30] G. de Felice, Experimental Investigation on Historic Brickwork Subjected to Eccentric Axial Loads, in: P.B. Lourenço, P. Roca, C. Modena, S. Agrawal, (Eds.), Struct. Anal. Hist. Constr., New Delhi, 2006, pp. 809-816.

[31] A. Costigan, S. Pavia, Compressive, flexural and bond strength of brick/lime mortar masonry, in: Proceedings of PROHITEC 09., 2009, pp. 1609-1615.

[32] C. Cornadó, Comportament mecànic-estructural dels edificis històrics de murs d'obra de fàbrica de maó de l’Eixample de Barcelona, Ph. D. thesis, Universitat Politècnica de Catalunya, Spain, 2015.

[33] European Committee for Standardization (CEN), EN 772-1: Methods of Test for Masonry Units - Part 1: Determination of Compressive Strength, (2011).

[34] European Committee for Standardization (CEN), EN 772-6: Methods of Test for Masonry Units - Part 6: Determination of Bending Tensile Strength of Aggregate Concrete Masonry Units, (2002). 
[35] European Committee for Standardization (CEN), EN 12390-13: Testing hardened concrete - Part 13: Determination of secant modulus of elasticity in compression, (2013).

[36] European Committee for Standardization (CEN), EN 1015-11: Methods of test for mortar for masonry Determination of flexural and compressive strength of hardened mortar, (1999).

[37] American Society for Testing and Materials, ASTM C 469-02 Standard Test Method for Static Modulus of Elasticity and Poisson’s Ratio of Concrete in Compression, (2002).

[38] European Committee for Standardization (CEN), EN 14580 Natural stone test methods. Determination of static elastic modulus, (2006).

[39] L. Pelà, E. Canella, A. Aprile, P. Roca, Compression test of masonry core samples extracted from existing brickwork, Constr. Build. Mater. 119 (2016) 230-240. doi:10.1016/j.conbuildmat.2016.05.057.

[40] American Society for Testing and Materials, ASTM E111 Standard Test Method for Young's Modulus, Tangent Modulus, and Chord Modulus, (2010).

[41] K. Naraine, S.N. Sinha, Loading and unloading stress-strain curves for brick masonry, J. Struct. Eng. 115 (1989) $2631-2644$.

[42] European Committee for Standardization (CEN), Eurocode 6: Design of masonry structures - Part 1: General rules for reinforced and unreinforced masonry structures, (2005).

[43] ACI, ASCE, TMS, Commentary on Specification for Masonry Structures (ACI 530.1-02/ASCE 6-02/TMS 60202), (2004).

[44] H.K. Hilsdorf, Investigation into the failure mechanism of brick masonry loaded in axial compression. Designing, Engineering and Constructing with Masonry Products., Houston, Texas, 1969.

[45] C.L. Khoo, A.W. Hendry, Strength tests on brick and mortar under complex stresses for the development of a failure criterion for brickwork in compression, Proc Br Ceram Soc. 21 (1973) 57-66.

[46] A. Ohler, Zur berechnung der druckfestigkeit von mauerwerk unter berücksichtigung der mehrachsigen spannungszustande in stein und mortel, Bautechnik. 63 (1986) 163-168.

[47] P.B. Lourenço, J. Pina-Henriques, Validation of analytical and continuum numerical methods for estimating the compressive strength of masonry, Comput. Struct. 84 (2006) 1977-1989. doi:10.1016/j.compstruc.2006.08.009.

[48] European Committee for Standardization (CEN), Eurocode 2: Design of concrete structures. General rules and rules for buildings, (2004).

[49] ACI, ASCE, TMS, ACI 530-05/ASCE 5-05/TMS 402-05 Building Code Requirements for Masonry Structures, (2005). 
[50] G.N. Pande, J.X. Liang, J. Middleton, Equivalent elastic moduli for brick masonry, Comput. Geotech. 8 (1989) 243-265. doi:10.1016/0266-352X(89)90045-1.

[51] J. Eibl, E. Keintzel, V. Vratsanou, Determination of earthquake duration dependent behaviour factors for unreinforced brick masonry panels by nonlinear time history calculations, in: Proceedings of Elev. World Conf. Earthq. Eng. (1996).

[52] K. Subramaniam, S.N. Sinha, Analytical Model for Cyclic Compressive Behavior of Brick Masonry, ACI Struct. J. 92 (1995) 288-294.

[53] M.M. AlShebani, Cyclic residual strains of brick masonry, in: Proceedings of Int. Conf. Struct. Eng. Mech. Comput., 2001.

[54] M.E. Nazar, S.N. Sinha, Loading-unloading curves of interlocking grouted stabilised sand-flyash brick masonry, Mater. Struct. Constr. 40 (2007) 667-678. doi:10.1617/s11527-006-9177-X.

[55] J.F. Sima, P. Roca, C. Molins, Nonlinear response of masonry wall structures subjected to cyclic and dynamic loading, Eng. Struct. 33 (2011) 1955-1965. doi:10.1016/j.engstruct.2011.02.033.

[56] F.J. Crisafulli, Seismic Behaviour of Reinforced Concrete Structures with Masonry Infills, University of Canterbury, 1997.

[57] K. Naraine, S. Sinha, Cyclic behavior of brick masonry under biaxial compression, J. Struct. Eng. 117 (1991) 1336-1355.

[58] I. Galman, Ściany z ceramicznej cegłypełnej cyklicznie ściskane w swej płaszczyźnie lub zginane prostopadle do płaszczyzny, Ph. D. thesis, Silesian University of Technology, Poland, 2012.

[59] H.B. Kaushik, D.C. Rai, S.K. Jain, Stress-Strain Characteristics of Clay Brick Masonry under Uniaxial Compression, J. Mater. Civ. Eng. 19 (2007) 728-739. doi:10.1061/(ASCE)0899-1561(2007)19:9(728).

[60] A.M. Wolde-Tinsae, J. Colville, R.H. Najib, Modulus of elasticity of clay brick masonry, in: Proceedings of 9th Int. Brick Block Mason. Conf., 1991.

[61] P.B. Lourenço, Recent Advances in Masonry Modelling: Micromodelling and Homogenisation, Multiscale Model. Solid Mech. (2009) 251-294. doi:10.1142/9781848163089_0006. 